NBER WORKING PAPER SERIES

IDENTIFYING SUPPLY AND DEMAND ELASTICITIES OF AGRICULTURAL COMMODITIES: IMPLICATIONS FOR THE US ETHANOL MANDATE

\author{
Michael J. Roberts \\ Wolfram Schlenker \\ Working Paper 15921 \\ http://www.nber.org/papers/w15921 \\ NATIONAL BUREAU OF ECONOMIC RESEARCH \\ 1050 Massachusetts Avenue \\ Cambridge, MA 02138 \\ April 2010
}

We would like to thank Jim Hamilton, Randall Walsh, and seminar participants at Berkeley, Cornell, Iowa State University, NBER Agricultural Economics Conference, Stanford, University of British Columbia, University of Calgary, and the University of Maryland for useful comments. All remaining errors are ours. Financial support from Department of Energy Grant DE-FG02-08ER64640 is thankfully acknowledged. The views expressed herein are those of the authors and do not necessarily reflect the views of the National Bureau of Economic Research.

NBER working papers are circulated for discussion and comment purposes. They have not been peerreviewed or been subject to the review by the NBER Board of Directors that accompanies official NBER publications.

(C) 2010 by Michael J. Roberts and Wolfram Schlenker. All rights reserved. Short sections of text, not to exceed two paragraphs, may be quoted without explicit permission provided that full credit, including ( $)$ notice, is given to the source. 
Identifying Supply and Demand Elasticities of Agricultural Commodities: Implications for the US Ethanol Mandate

Michael J. Roberts and Wolfram Schlenker

NBER Working Paper No. 15921

April 2010

JEL No. D61,Q11

\begin{abstract}
$\underline{\text { ABSTRACT }}$
We present a new framework to identify demand and supply elasticities of agricultural commodities using yield shocks - deviations from a time trend of output per area, which are predominantly caused by weather fluctuations. Demand is identified using current-period shocks that give rise to exogenous shifts in supply. Supply is identified using past shocks, which affect expected future prices through inventory accretion or depletion. We use our estimated elasticities to evaluate the impact of ethanol subsidies and mandates on world food commodity prices, quantities, and food consumers' surplus. The current US ethanol mandate requires that about 5 percent of world caloric production from corn, wheat, rice, and soybeans be used for ethanol generation. As a result, world food prices are predicted to increase by about 30 percent and global consumer surplus from food consumption is predicted to decrease by 155 billion dollars annually. If a third of the biofuel calories are recycled as feed stock for livestock, the predicted price increase scales back to 20 percent. While commodity demand is extremely inelastic, price response is muted by a significant supply response that is obscured if futures prices are not instrumented. The resulting expansion of agricultural growing area potentially offsets the $\mathrm{CO} 2$ emission benefits from biofuels.
\end{abstract}

Michael J. Roberts

North Carolina State University

michael_roberts@ncsu.edu

Wolfram Schlenker

Department of Economics

School of International and Public Affairs

Columbia University

420 West 118th Street, MC 3323

New York, NY 10027

and NBER

wolfram.schlenker@columbia.edu 
The rapid ascent of commodity prices between 2006 and 2008 led to a renewed debate about what drives the demand and supply for basic food commodities. Corn prices nearly quadrupled from about $\$ 2.00$ per bushel to almost $\$ 8.00$ per bushel and prices for rice, soybeans, and wheat rose by similar amounts. High prices for these staple grains caused hunger, malnutrition, and riots in a number of developing nations, as was vividly reported in the popular press. The price spike was attributed to a number of factors, including the prolonged drought in Australia, accelerating demand growth due to the broad scale economic development in Asia, and a shift in demand stemming from the United States ethanol policy. The combination of ethanol subsidies, restrictions on ethanol imports, and high oil prices caused a formerly nascent ethanol industry to quickly grow into one that consumes approximately one third of the United States corn production and about five percent of the world's combined caloric production of corn, soybeans, wheat and rice. Evaluating how much the biofuel mandated contributed to higher prices requires estimates of the underlying supply and demand elasticities.

A closely connected issue is land use change. Land used in commodity production might alternatively be used for pasture or forests, which generally sequester more $\mathrm{CO}_{2}$ than does crop production. This has ignited an active debate about the potential benefits of using biofuels to reduce $\mathrm{CO}_{2}$ emissions. For example, the Washington Post reported on February 4, 2010 that "The Environmental Protection Agency said new data showed that, even after taking into account increased fertilizer and land use, corn-based ethanol can yield significant climate benefits by displacing conventional gasoline or diesel fuel." The article cites Tim Searchinger with the counterpoint, "The [Environmental Protection Agency's] numbers are inconsistent with the great bulk of analyses by others, which consistently find that emissions from indirect land-use change for crops grown on productive land cancel out the bulk or all of the greenhouse gas reductions, but I will have to study the results." A crucial point of disagreement in the literature is how much the biofuel standard increase commodity prices, and thereby induce expansion of growing area. The potential size of this effect is nontrivial, as land use change (mainly deforestation) is thought to account for about 20 percent of worldwide $\mathrm{CO}_{2}$ emissions (IPCC 2007). ${ }^{1}$

Another discussion that requires estimates of the demand and supply elasticities of agricultural involves "leakage" from carbon offset programs that pay farmers to either forestall

\footnotetext{
${ }^{1}$ Holland et al. (2009) find that a low-carbon fuel standard, which limits the carbon intensity of fuels might actually increase $\mathrm{CO}_{2}$ emissions as it increases the price of high-carbon fuels but decreases the price of low-carbon fuels. The implicit subsidy on the latter might decrease the price of low-carbon fuels, increasing demand and total emissions.
} 
deforestation or reforest land that would otherwise be used in crop production. Carbon offset programs shift the supply of cropland inward, causing commodity prices to rise, and thus an offsetting increase in the quantity of cropland supplied elsewhere. The global net offset can therefore be much less than the offset purchased in any particular location. The amount of leakage depends on size of the supply elasticity relative to the demand elasticity.

With these key applications in mind, this paper develops a new framework to empirically identify both supply and demand elasticities for the world's four most important staple food commodities: wheat, rice, corn and soybeans. These commodities comprise about 75 percent of the caloric content of food production worldwide. ${ }^{2}$ While many other commodities matter for food consumption, and the particular mix of foods varies across locations, we limit ourselves to these four crops. It seems unlikely for the prices and quantities of other staple food items not to be inextricably linked to these four commodities given that these commodities figure so predominantly in the world food system. Indeed, as we will show below, the prices of these four commodities tend to fluctuate closely together. We simplify matters further by aggregating these four key crops on either a caloric or value-weighted basis.

Agricultural commodity markets, with their many price-taking producers and buyers and well-developed spot and futures markets, are often cited as the archetype of perfect competition. The key empirical challenge is to separate supply and demand in the market's formation of prices and quantities. Correct identification requires instruments that shift prices in ways that are plausibly unrelated to unobservable shifts in each curve. Since Wright's (1928) introduction of instrumental-variable estimation, weather has been considered a natural instrument for agricultural supply shifts, which can be used to facilitate unbiased demand estimation. The idea is that weather shifts supply in a manner that is unrelated to unobserved demand shifts. Given this idea was established long ago we find it surprising that the literature in agricultural economics that uses weather-based instruments to identify demand is extremely thin.

Here we show how yield shocks that are due to random weather shocks can also be used to identify supply. The idea follows naturally from the theory of competitive storage: past shocks exogenously shift inventories, which affects expected future prices, which in turn causes a future production response. Thus, past shocks can serve as instrument for futures prices.

\footnotetext{
${ }^{2}$ Cassman (1999) attributes two-thirds of world calories to corn, wheat, and rice. Adding soybean calories brings the share to 75 percent.
} 
Our approach to supply estimation differs from a large existing literature that stems from the seminal work of Nerlove (1958). In this literature supply is estimated by regressing quantities against uninstrumented futures prices, lagged prices, or prices predicted from an autoregressive model. Nerlove's approach purges endogeneity stemming from current unanticipated supply shocks, like the weather shocks Wright suggested be used for identification of demand. But because futures prices reflect the intersection of anticipated supply and anticipated demand, the standard approach does not account for endogeneity stemming from anticipated supply shifts that are unobserved to the econometrician. Because these unobserved supply shifts are the natural interpretation of the error in a supply equation with futures prices on the right-hand-side of the regression, endogeneity remains a serious concern. This is perhaps one reason why this substantial literature on agricultural supply response finds widely varying supply elasticities that often lack statistical significance (Askari and Cummings 1977).

A recent example from the United States illustrates the endogeneity of futures prices in the supply equation. In the spring of 2004 soybean rust (a fungus) was first detected in the United States. Although soybean rust is manageable, fungicides used to control it are expensive. In the subsequent growing season, fear of the pest caused some farmers to switch from planting soybeans to planting corn. These supply shifts were anticipated in advance, causing futures prices for soybeans to rise and futures prices for corn to fall-clearly movements along the demand curves for these key crops. In other words, the planted area did not decrease because prices went up, but prices went up because there was an unobserved shift in supply (stemming from fear of soybeans rust) that lowered area planted and expected harvest. In subsequent years the perceived threat of this new pest abated, causing additional supply fluctuations as relative prices returned to normal. A naive econometrician, regressing quantity supplied of either corn or soybeans on futures prices, would estimate a supply elasticity biased towards zero due to the soybean rust phenomenon, because the potential pest threat (part of the error term) was correlated with the expected future price. While this is just one example, it should be clear that, when using the standard approach to supply estimation, any number of anticipated supply shifts that are either unobservable or unmeasurable to the econometrician would cause downward bias in estimated supply response.

Our first approach to estimation of supply and demand exploits yield shocks - deviations from country and crop-specific yield trends that appear to stem mainly from random weather shocks. A potential shortcoming of this approach is that yields themselves may be 
endogenous to price. We explore this potential issue in detail and argue that any short-run causal links going from price to yield are likely minimal. We also consider estimates derived from weather-based instruments, which are more defensibly exogenous. The obvious tradeoffs between using yield shocks and weather variables as instruments are between statistical power, endogeneity bias and weak-instruments bias. Despite these tradeoffs, a wide variety of estimates using different specifications and instruments show remarkable consistency, and most estimates have strong statistical significance.

We use the demand and supply model of world commodity calories to examine the effect of the current United States biofuel mandate on food prices. This analysis provides some perspective on rapid price increase between 2006 and 2008 and how much of it might have been attributable to ethanol policy. Our estimates indicate that supply is more elastic than demand, with almost all of the supply response coming from the extensive margin, i.e., an expansion of land area. Both supply and demand elasticities are significantly larger, both economically and statistically, than uninstrumented estimates derived using traditional techniques. The estimates suggest that the US ethanol mandate increased food prices about 30 percent and increased world production area by 2 percent. The baseline estimate for the price increase does not incorporate any recycling of the corn used to produce biofuels as feedstock, which will reduce the predicted price increase proportionally. For example, if one third of the calories used to produce biofuel are contained in the waste product that is fed to animals, the price increase would be 20 percent. While these predicted effects are substantial they suggest that other factors likely played a larger role in the 2006-2008 price boom.

At the same time, a 30 percent price increase implies an annual loss of 155 billion in consumer surplus. While most of this is offset with an increase in producer surplus, the US ethanol policy results in transfers from net food importers to next food exporters. Since most developing countries are net food importers, they are especially impacted. Moreover, an increase in world food prices for a food importer is equivalent to a reduction in income, which has been shown to result in an increase in civil conflicts (Miguel et al. 2004, Burke et al. 2009). The US biofuel policy therefore has significant distributional consequences. This is in line with earlier research about other policies that aim to reduce $\mathrm{CO}_{2}$ emissions. Bento et al. (2009) examine the markets for new and used cars and find that the distributional consequences of a gasoline tax crucially depend on how the revenues are recycled. Similarly, (Li et al. 2009) find that higher gasoline taxes not only change the fuel economy of new cars, but also lead to increased scrappage of old inefficient cars, which are primarily owned by less 
affluent people.

\section{A Model of Supply and Demand}

We simplify our characterization of world food commodity market by transforming quantities of maize, wheat, rice, and soybeans into caloric equivalents and then aggregating them (Roberts and Schlenker 2009). In sensitivity check we also aggregate on the basis of average price. Aggregating crops facilitates a simple yet broad-scale analysis of the supply and demand of staple food commodities on a worldwide scale. A practical reason for aggregation is that prices for all four commodities tend to vary synchronously, which seriously impedes identification of multiple cross-price elasticities and separating cross-price elasticities from own-price elasticities. The strong correlation of prices over time also suggests that substitution possibilities are large enough that the aggregate outcomes likely characterize all four markets reasonably well. Perhaps the greatest concern comes from combining calories from wheat and rice with those derived from corn and soybeans. Most wheat and rice is directly processed into food people eat while corn and soybeans are mainly used for animal feed and thus form the caloric basis for most meat and dairy products. In another sensitivity check discussed below we therefore test whether the shocks from corn and soybeans have different influence on aggregate price than do rice and wheat shocks, but we find no evidence for this.

\subsection{Theoretical Motivation}

Having reduced the staple food commodity market to a single caloric measure, we need a model that characterizes supply, demand and inventories and how random shocks facilitate identification of the supply and demand elasticities. The theory of competitive storage sits at the heart of this approach. Storage is a characteristic feature of all four commodities we consider. It allows for substitution of consumption over time by transferring commodities from periods of relative scarcity to periods of relative plenty. Consumption is smoother than production and prices are less variable and more autocorrelated than they would be without storage opportunities. Equilibrium in each period does not require a price where supply in the current period equals consumption demand in the current period, but a price where the amount consumed $c_{t}$ equals food supply at the beginning of the period $z_{t}$ minus the amount stored (denoted $x_{t}$ ).

$$
c_{t}=z_{t}-x_{t}
$$


An extensive literature on the rational competitive storage model characterizes the demand for inventories and the resulting price path of commodities. Our focus differs from this literature, but we do exploit the above identity and other essential characteristics of storage models.

Scheinkman and Schechtman (1983) and Bobenrieth H. et al. (2002) set up a model in which profit-maximizing agricultural producers make two decisions. The first is how much to store and carry over to the next period, $x_{t}$. Storage has convex cost $\phi\left(x_{t}\right)$. The amount not stored $z_{t}-x_{t}$ is consumed and gives consumers utility $u\left(z_{t}-x_{t}\right)$. The second decision is how much "effort" $\lambda_{t}$ to put into new production, which is subject to a multiplicative i.i.d. random weather shock $\omega_{t+1}$ that is unknown at the time of planting. One possible interpretation of $\lambda_{t}$ is that it specifies the number of acres a farmer plants. Production in the coming harvest season is $s_{t+1}=\lambda_{t} \omega_{t+1}$, where $\omega_{t+1}$ is the distribution of yields, which are impacted by exogenous weather shocks. The production cost $g\left(\lambda_{t}\right)$ are assumed to be convex, as land of heterogenous quality becomes progressively more expensive to farm.

The Bellman equation for the social maximization problem is

$$
\begin{aligned}
v\left(z_{t}\right)= & \max _{x_{t} \lambda_{t}}\left\{u\left(z_{t}-x_{t}\right)-\phi\left(x_{t}\right)-g\left(\lambda_{t}\right)+\delta \mathbb{E}\left[v\left(z_{t+1}\right)\right]\right\} \quad \text { subject to } \\
& z_{t+1}=x_{t}+\lambda_{t} \omega_{t+1} \\
& x_{t} \geq 0, \quad z_{t}-x_{t} \geq 0, \quad \lambda_{t} \geq 0
\end{aligned}
$$

Competitive price-taking producers and storers achieve the socially optimal outcome by optimally balancing the marginal cost of effort against expected price and the marginal cost of storing agricultural goods against the expected change in prices. In the social planner's problem, price is reflected by the marginal utility of consumption. Increasing storage levels are profitable in years when availability $z_{t}$ is sufficiently large, which causes the current price to be low. By shifting some of the current availability into the next period, current prices rise and the expected price in the next period falls. This process continues up to the point when the discounted future price equals the current price. By the same token, prices rise if availability $z_{t}$ decreases. Prices tend to spike most after multiple negative shocks such that inventories are drawn very low. We observe this behavior empirically: price spikes are exceptionally steep if inventory levels remain low for several periods. If the weather shock is sufficiently negative, inventories theoretically may be drawn to zero, even though this is rarely observed in practice. ${ }^{3}$

\footnotetext{
${ }^{3}$ In the absence of convenience yield, a stockout theoretically occurs when prices are high enough that
} 
Scheinkman and Schechtman (1983) show that in a competitive equilibrium:

(i) consumption $c_{t}=z_{t}-x_{t}$ is strictly increasing in $z_{t}$

(ii) storage $x_{t}$ is weakly increasing in $z_{t}$

(iii) effort $\lambda_{t}$ is weakly decreasing in $z_{t}$

For our purposes, the key result from this model is that it implies exogenous shocks are optimally divided between current consumption and inventory adjustments. We can infer this because random shocks randomly shift $z_{t}$. Thus, bad weather shocks exogenously reduce $z_{t}$ thereby reducing consumption and increasing price, and vice versa for positive weather shocks (i), which captures movement along the demand curve. The same negative weather shocks also draw down inventories, reducing consumption and increasing price in subsequent periods (ii). And when storage levels are low and the expected price in the next period is high, farmers increase the amount planted $\lambda_{t}$ (iii), which captures movement along the supply curve.

\section{$1.2 \quad$ Empirical Model}

The empirical model is

$$
\begin{aligned}
\text { Supply: } & \log \left(s_{t}\right) & =\alpha_{s}+\beta_{s} \log \left(\mathbb{E}\left[\left.p_{t}\right|_{t-1}\right]\right)+\gamma_{s} \omega_{t}+f(t)+u_{t} \\
\text { Demand: } & \log \left(z_{t}-x_{t}\right) & =\alpha_{d}+\beta_{d} \log \left(p_{t}\right)+g(t)+v_{t}
\end{aligned}
$$

Quantities supplied and demanded are denoted by $s_{t}$ and $z_{t}-x_{t}$, respectively; $p_{t}$ is price, which equals the marginal willingness to pay for quantity demanded; the parameters $\beta_{s}$ and $\beta_{d}$ are supply and demand elasticities; $\omega_{t}$ is the random weather-induced yield shock; $\alpha_{s}$ and $\alpha_{d}$ are intercepts; and $f(t)$ and $g(t)$ capture time trends in supply and demand, stemming from technological change, population, and income growth. The errors $u_{t}$ and $v_{t}$ are other unobserved factors that shift supply and demand.

the expected subsequent price change becomes negative. If, however, $\omega_{t+1}$ is allowed to have a mass point at zero, i.e., a non-zero probability that the entire harvest is wiped out, and $\lim _{c \rightarrow 0} u^{\prime}(c)=\infty$, then the long-run distribution has a finite price, inventories will be positive with probability one, and the mean of the price distribution is infinite (Bobenrieth H. et al. 2002). While low inventory levels (and high prices) will almost surely result in subsequent price declines, the expected price is still increasing. The rationale is that if another bad shock occurs, the already strained market would result in a very large price jump. The resulting payoff is so large that it always justifies holding positive inventories. 
Because farmers make planting decisions before a year's weather shock or other supply or demand shocks are realized, supply is linked to expected prices. It is therefore standard to use futures prices one year in advance to more accurately measure farmer expectations. Specifically, we use future prices for corn in December of period $t-1$ for a December delivery in period $t$. For soybeans we use futures prices in November, and for wheat we use futures prices in September. Each month constitutes the end of the growing season in the Northern hemisphere. For demand we use current-year prices.

Prices are the key endogenous variables on the right-hand side of both supply and demand. The crux of the identification problem is to identify supply and demand elasticities given that unobserved shifts in supply and demand $\left(u_{t}\right.$ and $\left.v_{t}\right)$ influence prices via the equilibrium identity. Without correcting for the endogeneity of prices, the supply elasticity would be biased negatively, since unobserved positive supply shifts $\left(u_{t}\right)$ would tend to reduce price all else the same, creating a negative correlation between $u_{t}$ and price. A naive demand elasticity (without correcting for the endogeneity of prices) would tend to be biased positively, since unobserved positive demand shifts $\left(v_{t}\right)$ would tend to increase price all else the same, creating a positive correlation between $v_{t}$ and price. If unobserved supply and demand shifters $u_{t}$ and $v_{t}$ are correlated, biases could go in either direction.

We use concurrent and/or lagged yield shocks to identify demand and supply. Our baseline proxy for weather-induced yield shocks are deviations from country-specific trends in yield (tons per hectare) for each crop. Country-and-crop-specific deviations are then converted to calories and aggregated to obtain a world supply shock. Our premise is that these deviations from yield trends are exogenous as they largely due to random weather. One potential concern is that yields themselves might be a function of prices. For example, higher prices could induce farmers to choose higher sowing densities, thereby increasing average yields. On the other hand, higher prices might induce farmers to expand their production to marginal, less productive, land, thereby lowering average yields. It is hence unclear a priori which way the bias would go. We believe that endogenous yield responses are not important in our paper for several reasons: First, farm and county-level data show considerable variability in deviations from a yield trend but have almost no autocorrelation (Roberts and Key 2002, Roberts et al. 2006), while prices have a very high degree of autocorrelation. If yields endogenously respond to prices, then yields would show autocorrelation as well. Second, if yields were responsive to price levels, we would observe that yield shocks are correlated between various countries in a given year, as all countries face the same world price. In Figure 4 below, we show scatter plots of yield deviations for the two biggest producers 
of our four commodities. These plots show no systematic correlation: two of the four even have negative correlation coefficients. While some endogenous yield response is likely present, these stylized facts suggest it is small relative to variation induced by weather shocks. In one of our sensitivity check we directly instrument for yield shocks with weather variables. The challenges with using weather-based instruments are (a) obtaining and linking world-wide fine-scaled weather data to growing areas and (b) finding a few weather variables strongly associated with yield.

The yield shocks are calculated as proportion of predicted output by area. To gain statistical power we divide the shocks by inventories because competitive storage theory and empirical evidence suggest shocks have more influence on price when inventories are low. Prominent examples include the recent price spike and the one in the 1970s, both of which occurred in an environment with unusually low inventories. If yield shocks are linearly independent of other supply or demand shifters, then multiplying yield shocks with inventory levels is also linearly independent of those shifters. ${ }^{4}$

The first stage regressions relate natural log of prices and the natural log of futures prices against current and lagged yield shocks $\omega_{t}$ up to lag $K$, plus a polynomial time trend up to order $I .{ }^{5}$ The first-stage regressions are thus:

$$
\begin{aligned}
\log \left(p_{t}\right) & =\pi_{d 0}+\sum_{k=0}^{K-1} \mu_{d k} \omega_{t-k}+\sum_{i=1}^{I} \rho_{d i} t^{i}+\epsilon_{d t} \\
\log \left(\mathbb{E}\left[\left.p_{t}\right|_{t-1}\right]\right) & =\pi_{s 0}+\sum_{k=0}^{K} \mu_{s k} \omega_{t-k}+\sum_{i=1}^{I} \rho_{s i} t^{i}+\epsilon_{s t}
\end{aligned}
$$

In the second stage we estimate the structural equations (1) and (2), substituting the predicted values of price from the first stage in place of actual prices. For the supply equation (1) we regress the natural log of production quantity against the predicted futures price $\log \widehat{\left(\mathbb{E}\left[\left.p_{t}\right|_{t-1}\right]\right)}$, a polynomial time trend up to order $I$ as a proxy for $f(t)$ and the supply shifter in the current period $\omega_{t}$. Stage-one variables excluded from the stage-two supply equation are lagged yield shocks $\omega_{t, t=t-K-1, \ldots, t-1}$ which serve as instruments. The stage-two

\footnotetext{
${ }^{4}$ In another cross-check we use the raw yield shocks as instruments.

${ }^{5}$ The first stage of expected price used in the supply equation includes the shock $\omega_{t}$ as it is included as a supplier shifter in the second stage. Since the expected price is traded in period $t-1, K$ lags runs from $t-1$ to $t-K-1$.
} 
regression model of supply is:

$$
\left.\left.\log \left(s_{t}\right)=\alpha_{s}+\beta_{s} \log \widehat{\left(\mathbb { E } \left[\left.p_{t}\right|_{t-1}\right.\right.}\right]\right)+\lambda_{s 0} \omega_{t}+\underbrace{\sum_{i=1}^{I} \tau_{s i} t^{i}}_{f(t)}+u_{t}
$$

For the demand equation (2) we regress the natural log of quantity consumed on predicted price, a polynomial time trend up to order $I$ as a proxy for $g(t)$. The stage-one variable excluded from the stage-two demand equation are the supply shocks $\omega_{t, t=t-K, \ldots, t}$. The stagetwo regression model of demand is:

$$
\log \left(s_{t}-x_{t}\right)=\alpha_{d}+\beta_{d} \widehat{\log \left(P_{t}\right)}+\underbrace{\sum_{i=1}^{I} \tau_{d i} t^{i}}_{g(t)}+v_{t}
$$

\subsection{Identification of Demand}

Wright (1928) was first to use weather as an instrument for demand identification when he introduced the instrumental variables technique. A key difference from Wright is that we simultaneously consider the four key commodities that are substitutes in supply and demand. It is important to consider these crops simultaneously to ensure that effects on crops that are substitutes in production do not confound own-price elasticities with cross-price elasticities. We aggregate the caloric value of all four crops. Future research might simultaneously estimate equations for all crops, including cross-price elasticities, but identification could be more challenging given the limited number of observations.

Consistent identification of the demand elasticity $\beta_{d}$ requires that the instrument shifts supply in a way that is plausibly unrelated to unobserved shifts in demand. Technically, $\omega_{t}$ must have a zero covariance with $v_{t}$. Weather is a natural instrument for three reasons. Weather is clearly exogenous in an economic sense because weather affects farmers but farmers cannot affect weather. Second, from the vantage point of farmers, weather is unpredictable and nearly random at planting time, except perhaps for some cycles like El Nino. The near randomness of weather suggests that it wouldn't be generally related to broader economic conditions having to do with demand. Third, while weather has an obvious causal connection to supply of agricultural commodities, it would generally seem to have little or no direct influence on demand. It is of course possible that weather could shift tastes, hunger, or general caloric need. For example, extreme heat may simultaneously harm crop yields 
and make people or animals less physically active thereby reducing demand. It is difficult to imagine that these demand-related effects could be large. In a global context, however, it becomes even less of a concern. This is because there are well-established international markets with a significant share of production traded both within and between regions and nations. As a result, the weather that affects crop production tends to be far removed from demand centers. For example, most of the feed grains used for hog and poultry production in North Carolina comes from the Midwest where weather fluctuations are quite unrelated.

For our baseline regressions, however, we do not use weather based instruments. Instead we use yield shocks: deviations from local trends in output per acre. While yields shocks are obviously more connected to supply than weather variables, a potential problem with this instrument is that an unobserved demand shock would influence expected price, and perhaps cause farmers to apply more effort or inputs per acre, thereby raising yields. This might potentially create a positive correlation between yield shocks and unobserved demand shocks and therefore bias the demand elasticity toward zero. Our main defense against this criticism is that yield shocks appear random like the weather does, as we will demonstrate below. In a second step we use weather data from around the world to link yearly country-specific yields to weather outcomes including time trends to capture technological innovations. Once the link between weather outcomes and yields is established, yield shocks are constructed by multiplying the estimated weather coefficients with weather shocks, which we define to be deviations from average weather outcomes.

It may be tempting to use deviations from the trend in world production as a proxy for aggregate weather shocks. Such an approach can be misleading because it still confounds supply and demand responses to price, including adjustments in growing area. Production shocks depend on changes in average yields (output per acre) and growing area. While the former plausibly stem from weather-induced yield shocks and are arguably exogenous, the latter, expansion in the production areas, are known before harvest is realized and hence responsive to expected prices. We provide empirical evidence of this below. We hence derive shocks solely from country and crop specific yield shocks. As discussed below, these have a much stronger (negative) association with price than aggregate production shocks, suggesting that it is indeed the former that are exogenous.

\subsection{Identification of Supply}

A novelty of our approach is that we use past yield shocks (or weather) to identify the supply elasticity $\beta_{s}$ in addition to the demand elasticity. As described in detail above, this is 
possible because past weather-induced supply shocks affect inventories and inventories affect expected price in subsequent periods. The key assumption for consistent identification of the supply elasticity is that past weather-induced supply shocks have zero covariance with unobserved supply shifters in the current period. Unobserved supply shifters might stem from recurrent or anticipated pest problems, like the example of soybean rust in the introduction, broad macroeconomic phenomena, governmental policies, or perhaps other factors. One concern may be that agronomic or weather factors are correlated over time. We address this potential concern in two ways. First, we show that yield and weather shocks display little autocorrelation. ${ }^{6}$ Second, we include current weather shocks in the supply equation. While current shocks must be excluded from the demand equation, including them in the supply equation increases precision by reducing the error variance while accounting for current supply shifts that may have been associated with past shocks. Thus, conditional on the current weather or yield shock, it's not clear how or why past weather or yield shocks might be related to unobserved supply shifters.

\section{Data}

World production and storage data are publicly available from the Food and Agriculture Organization (FAO) of the United Nations (http://faostat.fao.org/) for the years 1961-2007. The data include production, area harvested, yields (ratio of total production divided by area harvested), and stock variation (change in inventories) for each of the four key crops. The last variable is only available until 2003. In our model estimates below, we stop all series in 2003 because quantity demanded (which depends on changes in storage) is not available after 2003 and because it precedes the recent boom and bust in commodity prices. Variables are converted into edible calories using conversion factors by Williamson and Williamson (1942), which specify the caloric input per output quantity of various crops. Consumption (quantity demanded) is calculated as production minus the net change in inventories.

Data on quantities are displayed in Figure 1. The top panel displays the number of people that could be fed on a 2000 calories per day basis and how much each of the four commodities contributed to total caloric production. Maize has the biggest share while soybeans has the smallest share. Wheat and rice are in the middle and have roughly equal shares. One noteworthy fact is that the overall year-to-year fluctuations (top line) are predominantly

\footnotetext{
${ }^{6}$ Rice is an exception; however the other three commodities and aggregate yield shocks show little autocorrelation
} 
due to fluctuations in maize. More than half of all corn was traditionally produced in the United States and the bulk of that production is geographically concentrated in one region, the Midwestern corn belt. ${ }^{7}$ Other crops are less geographically concentrated and hence local weather shocks average close to zero when summed over the whole world. Thus, corn may contribute a larger share of world caloric variability simply because it's production is more geographically concentrated and thus more likely to experience correlated weather outcomes.

The bottom panel of Figure 1 shows production and consumption quantities. Two features are noteworthy: First, production and consumption have been trending up steadily, almost linearly. Both appear trend stationary. Second, fluctuations around trend production are small in proportion to the trend. Consumption fluctuations are even smaller due to smoothing from storage accumulation and depletion. The FAO series on stock variation, necessary for derivation of consumption, ends in 2003 and hence so does our demand estimate.

Yield shocks in our baseline model are calculated by taking jackknifed residuals from fitting separate yield trends for each crop in each country. ${ }^{8}$ Trends and shocks were estimated for any country with an average of 1 percent or more of world production for each of our four crops. The average share of world production between 1961-2007 is shown in Table 1. Remaining rest-of-world yields were pooled and treated as a single country for each crop. Yield shocks were derived from both linear and quadratic trends and showed small and statistically insignificant autocorrelation. Figure 2 displays fitted quadratic yield trends to all countries, while the fitted jackknifed residuals are shown in Figure 3. Figure 4 shows scatter plots of yield deviations of the two largest producers of each crop. The lack of significant correlation suggests that yields do not endogenously respond to price, which would induce correlation between countries as everybody faces the same world price, or at least that the endogenous yield response is swamped by the much larger variation induced by weather shocks.

We derive caloric shocks for each country and crop using the product of: (1) country-andcrop-specific yield shocks; (2) hectares harvested; and (3) the ratio of calories per production unit. The world caloric shock is simply the sum of all country-specific shocks of all crops, which is then scaled relative to the world trend in total caloric production. Aggregating country and crop specific yield shocks purges production variation stemming from endogenous land expansion or contraction. As emphasized in the modeling section, land expansions

\footnotetext{
${ }^{7}$ Today, the US still accounts for roughly 40 percent of world corn production.

${ }^{8}$ OLS residuals give biased estimates of the errors. Jackknifed residuals, derived by excluding the current observation when determining the current residual, give unbiased estimates of the error.
} 
are often correlated with components of the error (e.g., a pest outbreak) and incorporated in next period's expected price, while yield shocks should be primarily due to exogenous weather shocks. ${ }^{9}$

As described above, there is concern that yields might endogenously respond to anticipated price changes. In a sensitivity check we therefore construct yield shocks that can be explained through observed weather fluctuations. We fit regressions of log yields on various weather measures and a quadratic time trend. Yield shocks are derived as predicted changes in yields that are attributable to deviations in the weather variables from historic averages. For example, if the average temperature in a country is $15^{\circ} \mathrm{C}$, the yield shock attributable to a year with an average temperature of $16.5^{\circ} \mathrm{C}$ is 1.5 times the coefficient on average temperature. For the United States we use the fine-scale weather data set of Schlenker and Roberts (2009) with a piecewise linear function in temperature (degree days) and a quadratic in total precipitation for maize and soybeans. We model rice and wheat using a quadratic in average temperature as there is less agreement on the optimal bounds in the agronomic literature as well as a quadratic in total precipitation during the growing season. For all other countries in the world we use a quadratic in average temperature as well as total precipitation for each of the four crops in a panel setting, i.e., we include all countries that produce at least one percent of a crop as well as the rest of the world in one equation and include country fixed effects. Weather data from the Climate Research Unit (CRU) at the University of East Anglia gives monthly temperature and precipitation readings on a 0.5 degree grid for the entire world for the years 1901-2002 (Mitchell and Jones 2005). ${ }^{10}$ The growing season for each country was obtained from Sacks et al. (2010). ${ }^{11}$ Weather outcomes in a country are the area-weighted average of all grids that fall in a country, where the crop-specific area weights from Monfreda et al. (2008) are displayed in Figure 5. ${ }^{12}$

We obtain two price series. Our baseline model uses futures prices from the Chicago Board of Trade with a delivery month of December for maize, November for soybeans, and September for wheat. ${ }^{13}$ We construct the price $p_{t}$ as the average futures price during the

\footnotetext{
${ }^{9}$ We divide world yield shocks and inventories by the trend in production, estimated using a quadratic trend in our baseline. The estimated trend is close to being linear and a sensitivity check with a linear trends shows similar results.

${ }^{10}$ http://www.cru.uea.ac.uk/ timm/grid/CRU_TS_2_1.html (accessed November 2008)

${ }^{11}$ The authors provide planting and harvest dates on a 5 minute grid. http://www.sage.wisc.edu/download/sacks/crop_calendar.html (accessed January 2010). We include the entire months between planting and harvest. For example, if average planting is on April 8th and harvest on September 12th, we use weather data from April through September.

${ }^{12}$ The authors provide the fraction of each 5 minute grid cell that is used for various crops. http://www.geog.mcgill.ca/landuse/pub/Data/175crops2000/NetCDF/ (accessed November 2008).

${ }^{13}$ We use futures price for "No.2 yellow" for corn, "No.1 yellow" for soybeans, and "No.2 soft shell" for
} 
month when delivery occurred, i.e., in December of the delivery year for corn. The expected price $\mathbb{E}\left[\left.p_{t}\right|_{t-1}\right]$ is the average futures price in the delivery month one year prior to delivery. ${ }^{14}$ All prices are deflated by the Consumer Price Index. Prices for each commodity are converted to their caloric equivalent, with the world calorie price taken as world-production-weighted averages of the four commodities. Unfortunately, the futures price series for rice does not extend before 1985 and we hence use the production-weighted price of the three commodities.

A second price series with longer temporal coverage are those received by US farmers in the month of December of each year, publicly available from the US Department of Agricultural. The top panel of Figure 6 displays real price (annual cost of a 2000 calories per day diet in 2007 dollars). There has been a general downward trend of food prices. Prices per calorie move together for all four commodities, most notably maize, wheat and soybeans. This is not surprising, given that those three are close substitutes in production and consumption. For example, maize and soybeans (and to some degree wheat) are used as feed for livestock. If one were cheaper per calorie than the others, profit-maximizing farmers should switch to the cheaper input. Price fluctuations are proportionately much larger than quantity fluctuations in Figure 1. This suggests that both demand and supply are inelastic.

The bottom of panel of Figure 6 displays our two price series in black as well as production shocks (deviation from the quadratic production trend in percent) in grey. The solid black line shows the production-weighted average December price of all four commodities. The black dashed line shows the production-weighted average futures price at delivery for maize, soybeans, and wheat. Leaving out rice, for which we do not have a futures series dating back to 1961 gives comparable results. The figure demonstrates the first stage of our IV strategy: prices fluctuate negatively in comparison to yield-shocks. The lack of autocorrelation in the yield shocks suggest that these yield shocks are due to weather and not technological advances, which would result in deviations from the trend that are less transient.

Table 2 reports descriptive summary statistics on caloric prices, production, consumption, our constructed world aggregate yield shocks, and yield shocks interacting with inverse inventories.

Given the large trends in overall production due to population growth and technological change in Figure 1, all shocks are normalized around the upward production trend. Trend production is obtained by regressing aggregate caloric production on a time trend of the same order used to derive jackknifed residuals. The default is a quadratic time trend, but

\footnotetext{
wheat.

${ }^{14}$ In some cases the time series of a contract does not extend 12 months back and we hence take the average price in months closest to 12 months prior.
} 
we present sensitivity checks for a model with a linear trend below.

\section{US Ethanol Subsidies and Mandates}

Ethanol has a long history as a car fuel. Ford's Model-T was designed to run both on ethanol and petroleum, or arbitrary mixes of the two. Declining petroleum prices led to a slow phase out of ethanol as a fuel. Recent concerns about anthropogenic $\mathrm{CO}_{2}$ emissions have renewed interest in ethanol as a fuel substitute, even though the net effect is highly debated (Searchinger et al. 2008). Ethanol is currently being mixed with traditional petroleum in ratios up to 10 percent. Most cars can run on such fuel mixes. Modern flex-fuel cars are designed to run on fuel that is up to 85 percent ethanol.

One might wonder why US ethanol subsidies and mandates can have a measurable effect of world food prices? The answer is simply the size of the US market share. Figure 7 shows the US share of world caloric production over time. Yearly observation are shown as crosses, and a locally weighted regression (bandwidth of 10 years) is added in grey. The yearly ratio fluctuates somewhat due to weather-induced yield shocks, but the average share stays rather constant around 23 percent. There is a slight uptick during the boom years (late 1970s) before the US share falls again after the 1980-1982 recession that heavily impacted the agricultural sector as well. Farmland prices fell roughly one third between the 1982 and 1987 Census.

Given the dominant share of world caloric production, any policy that impacts US production might lead to repercussions on world markets. Ethanol production has risen rapidly over the last couple of years as shown in Figure $8 .{ }^{15}$ Ethanol subsidies and biofuel mandates require that a certain amount of fuel is derived from ethanol. The 2005 US energy bill mandated that 7.5 billion gallons of ethanol be used by 2012. The 2007 energy bill increased the mandate to 36 billion by 2022. Moreover, under the 2009 US Renewable Fuels Standard, refiners and fuel blenders are required to blend roughly 11 billion gallons of ethanol into gasoline. We examine the effect of the latter on world food prices/ Currently, most of the ethanol is produced from corn, and 11 billion gallons of ethanol would require roughly 4.23 billion bushels of corn (assuming an average of 2.6 gallons of ethanol per bushel of corn). This translates into roughly one third of US maize production in 2007 (13 billion bushels), or about 5 percent of world caloric production in 2007. The remains of corn that is used in ethanol production can still be used as feed stock for livestock, which is often labeled

\footnotetext{
${ }^{15} \mathrm{http}: / /$ www.ethanolrfa.org/industry/statistics/
} 
distiller's grain. While estimates vary, up to one third of the caloric input is said to be recoverable, but the nutritional content is debated. We therefore present two estimates: our baseline model uses a five percent increase in world caloric production (assuming that nothing is recycled) as well as a scenario where we assume that one third of the calories is recycled as feed stock.

While 5 percent of world caloric production would be required for 11 billion gallons of ethanol, the average daily US motor gasoline consumption is 0.39 billion barrels per day. ${ }^{16}$ The supply of approximately 8 percent of US gasoline consumption requires approximately 5 percent of world caloric production.

\section{Empirical Results}

Regression results of the two-stage least squares and three-stage least squares results are summarized in Table 3. Columns differ by the number of lagged shocks and the order of polynomial used for the time trend. Elasticity estimates in Table 3 are reasonably stable across models, varying between 0.08 and 0.13 for supply and -0.05 and -0.08 for demand. The top panel summarizes the demand and supply elasticity, as well as the predicted price increase from a ethanol mandate that puts 5 percent of current world caloric production into biofuels. The second panel displays the regression results. Adding additional lagged weather shocks in the last two columns changes the results by very little. The results differ more if we move from a second-order time polynomial (first two columns) to a third order time polynomial (last four columns). We most prefer estimates in the first two columns because the additional lagged yield shocks are statistically insignificant in the last two columns. Moreover, small-sample bias is known to be smallest in two stage least squares when there are fewer instruments (Nelson and Startz 1990). Unsurprisingly, the trend estimates show that demand has grown more slowly than supply, which accords with the general downward trend in prices and the increase in storage over time.

The first-stage regression has highly significant instruments $\omega_{t}$ for both the current price $p_{t}$ in the demand equation and the expected price $\log \left(\mathbb{E}\left[\left.p_{t}\right|_{t-1}\right]\right)$ in the supply equation as shown in Table 4. Comparison of the coefficients on $\omega_{t-1}$ in the future price regression and $\omega_{t}$ in the current price regression indicates the shock affects the futures price nearly as much the current price. This is consistent with storage theory wherein transitory shocks are smoothed over time giving rise to autocorrelation in prices. It is also interesting that $\omega_{t}$ is statistically

\footnotetext{
${ }^{16}$ Energy Information Administration: http://www.eia.doe.gov/basics/quickoil.html
} 
significant in the futures price regression. This indicates that shocks are at least partially forecastable. ${ }^{17}$

The supply and demand elasticities imply that the US ethanol mandates (which requires 5 percent of world caloric production to be diverted for ethanol) will increase prices by $\frac{0.05}{\beta_{s}-\beta_{d}}$. Since the predicted ratio includes the inverse of the predicted parameters, it will be convex and the expected value will be greater than the ratio evaluated at the expected values. We therefore take 1 million random draws from the joint distribution of the demand and supply elasticity. The mean impact as well as the $95 \%$ confidence interval are given in rows 5 and 6 of Table 3. The mean impact is fairly stable between various specification at stays around 30 percent. However, it should also be noted that the distribution is right skewed and the $95 \%$ confidence interval extends further to the right than to the left of the mean impact. The mean price increase implies a decrease in consumer surplus from food consumption equal to 155 billion dollars annually. ${ }^{18}$ As noted above, the baseline scenario assumes that the waste products from ethanol reduction are not fed to animals. Since studies differ in what fraction can be recycled, we report estimates assuming zero recycling, which can easily be scaled by the assumed recycling ratio as the ultimate price increase is linear in this recycling ratio. For example, in case one third of the calories could be recovered as feed stock, the price increase would scale to $20 \%$. There will also be a partially offsetting increase in producer surplus. On top of that, some authors have argued that the ethanol mandate increases fuel supply, thereby lowering fuel cost, which in turn benefits consumers (Rajagopal et al. 2007). The full welfare analysis therefore also requires assumption on the elasticity of supply of fuels that are beyond the scope of this paper. It is worth noting that the policy is a larger shift from consumer surplus to producer surplus.

Table 5 conducts a sensitivity analysis which includes separate yield shocks for corn and soybeans (index by subscript MS) and rice and wheat (indexed by subscript RW). The rational is that the latter are primarily used as food, while the former are also used as feed stock. One might hence wonder whether yield shocks from all four commodities can be pooled together. On the margin, caloric demand should equate the price per calorie produced or it would be better to substitute to another crop. While there are of course regional preferences for various food sources (rice is predominant in Southeast Asia while Europeans rely much

\footnotetext{
${ }^{17}$ The forecastibility of current shocks does not create bias in the supply equation because current shocks are not excluded from the second stage.

${ }^{18}$ The expected supply (along the trend line) is the equivalent of feeding 7.06 billion people for a year on 2000 calories per day, prices in 2007 were 74.12 dollars per person per year, and the 30 percent price increase will reduce consumption by 1.5 percent.
} 
more on wheat), all we need for the prices to move together in equilibrium is that some demanders (feed lots, food processing plants) are willing to substitute various crops on the margin. We find no evidence that shocks are different for the two sets of commodities as all Wald tests (reported in the last three columns of each panel) are not significantly different. Since we have a limited number of observations ( 43 years), we pool all shocks to limited then number of variables in our analysis.

Table 6 presents various sensitivity checks. Panel A reports the baseline results from Table 3. Panel B uses a linear time trend to obtain jackknifed residuals as well a linear trend in production. The results are insensitive whether we use a linear time trend or a quadratic time trend in the baseline results. The predicted price increase remains robust around 30 percent.

Panel $\mathrm{C}$ derives caloric shocks as the product of the jackknifed yield residuals and the predicted (as opposed to actual) harvested area along a quadratic time trend. The effect on the estimated results is very minor though as we are dealing with a second order effect, i.e., the product of changes in yield times changes in areas.

Panel D rescales the caloric conversions factors so that the average price between 1961 and 2003 is the same for all commodities. If various goods are substitutes in production, relative conversion factors are given by the price ratios. This allows us to back out the implicit conversation factors set by the market instead of using the ones by Williamson and Williamson (1942). The results change again very little supporting our hypothesis that it is feasible to aggregate all four crops based on caloric conversion factors.

Panel E uses a sensitivity check where the caloric shock $\omega_{t}$ is not normalized by the inventory levels. The results seem to become a bit more sensitive to the order of the time polynomial, which is picking up that there was a time period in the 1970s when inventory levels were low and prices spiked.

Panel F focuses on the planting dates in the Northern hemisphere: As before, expected futures prices for wheat with a September delivery are averaged in the previous September. However, we no longer use soybeans and maize price a year in advance (i.e., in November and December of the previous, respectively), but the average price in March of the delivery year, the month when planting decisions are made in most of the Northern hemisphere. These March prices can incorporate information about the harvest in the Southern hemisphere that farmers in the North can incorporate at the time of planting. Again, the results are robust to this change.

Finally, Table 7 presents results when we use yield residuals that are attributable to 
observed weather shocks in Panel B. Significance levels decrease in both the first stage and the second stage. Since the instruments are weak, the results should be considered cautiously. Generally, demand is inelastic, while supply elasticities fluctuate around our baseline estimates, although the confidence intervals are wider as well. Three-stage least squares gives smaller standard errors than two-stage least squares, which are comparable to our baseline estimates if we include one lag of the shock. While the results are consistent with our baseline estimates for the specification with one lag and 3SLS, the results are less robust to other modifications of the specification. The larger confidence intervals are due to the weather measures having limited predictive accuracy outside the United States. The correlation coefficient between yearly caloric shocks using (i) jackknifed residuals and using (ii) shocks attributable to observed weather shocks is 0.71 in the United States. Since the United States accounts for such a disproportional share of world caloric production, the correlation is still 0.51 if we aggregate shocks over all countries. This is further demonstrated in Figure 9 where we plot yield residuals as deviations from a time trend on the $\mathrm{x}$-axis and yield residuals using weather instruments on the y-axis for some of the biggest producers. The top left panel shows the United States where the scatter plots aligns reasonably well with the 45-degree line. However, the bottom row shows that our model linking yields to weather is fairly bad for China and Thailand, which both heavily rely on rice.

The main motivation of using weather-induced caloric shocks was to rule out that yields are endogenous to price and hence our caloric shock, which is derived as deviations from a quadratic time trend, might also be endogenous. Figure 9 provides further evidence that this unlikely. We color-coded the scatter plot by the futures prices (traded the year before the yield was realized). If yields are endogenous, we should observe distinct color patterns. For example, if yields respond positively to higher prices as farmers increase sowing densities, our caloric shocks derived as deviations from a time trend should be more positive when prices are high. This would imply that observations with a large $\mathrm{x}$-values should be predominantly shown in red colors, while negative x-values should be shown in blue colors. We find no such distinct color pattern.

Our new estimates are contrasted to other approaches in Table 8. The first two columns report elasticity estimates from seemingly unrelated regressions (SUR) without a first stage. That is, these models use raw endogenous price, not predicted price. They do account for observed supply shifters and the correlation of innovations $u_{t}$ and $v_{t}$. We include this regression mainly to illustrate likely endogeneity bias in comparison to 2SLS estimates in 
Table 3. The SUR regression gives extremely inelastic estimates of supply and demand, 0.016 for supply and -0.017 for demand. While the demand elasticity is statistically significant at the $10 \%$ level, the standard errors are small and (if assumptions are accepted, which is dubious) rule out elasticities less than -0.034 with 97.5 percent confidence. The supply is statistically insignificant, and again rule out elasticities greater than 0.34 with 97.5 percent confidence. The predicted price increase of an ethanol mandate (diverting 5 percent of world production) would be almost 200 percent.

Columns (3) to (6) of Table 8 follow the approach of Nerlove (1958) and include futures prices which are not instrumented. The estimated supply elasticity becomes lower and insignificant, which is in accordance with the previous literature on supply responses. The predicted price increase of an ethanol mandate (diverting 5 percent of world production) would be around 60 percent if we use the point estimates of the elasticities. The mean impacts are even higher as the predicted price increase is a convex function of the parameters. Our concern with this approach is that expected price incorporates anticipated area responses and is hence endogenous.

All models in Table 8 give smaller supply elasticities and hence the ethanol policy would lead to larger price increases and lower area expansions. Our model gives a lower predicted reduction in consumer surplus than previous approaches, yet the predicted impact is still sizable. The flip-side of a more elastic supply is that the dampened price increase comes at another potentially harmful effect: A predicted expansion in the agricultural area. Searchinger et al. (2008) and others have emphasized that this land conversion will lead to further $\mathrm{CO}_{2}$ emissions. Currently, land conversion already accounts for $20 \%$ of global $\mathrm{CO}_{2}$ emissions.

Panel A of Table 9 examines this further by regressing the log of total world growing area (for maize, rice, soybeans, and wheat) on the combined lagged production shock $\omega_{t-1}$ of all four commodities in the first two columns. The coefficient is negative and significant at the one percent level, i.e., the planting area moves in the opposite direction of the shocks: A bad yield shock leads to an expansion of the area and vice versa. Rational market participants will incorporate this area-response, as well as all other known information about planting areas, in their expectation of future prices, making the price endogenous. Our approach therefore only uses production shocks that are due to unpredictable yield shocks as an instrument and purges the analysis of possible area responses. We regress the log of total area on instrumented caloric prices in columns (3) through (6), suggesting an area elasticity of roughly 0.06-0.07. While this number is smaller than our supply elasticity estimates, it 
should be noted that if the more productive countries are the responsive ones, a less than one-to-one response between output increases and area increases is expected. For example, if countries which have twice the average yield increase the area by $6 \%$, total supply will increase by more than $6 \%$. Panels B through F replicate the analysis for individual countries and demonstrate that there are different sensitivities to world caloric shocks and world prices: Major producers and exporters like the United States and Brazil show an even larger elasticity, while more self-sufficient countries like India show smaller elasticities. Our land elasticity for Brazil is comparable to Barr et al. (2010), but larger for the US. ${ }^{19}$ Our estimated elasticities imply that total caloric production would increase by roughly 3.5 percent, or 180 trillion calories. Using an elasticity of 0.06 from Table 9 on the predicted 30 percent price change, total acreage is predicted to increase by 2 percent, or 30 million acres. In 2007, total planting area for the four commodities were 1.5 billion acres.

Table 10 shows the range of calories per hectare that can currently be obtained. Using the highest coefficient for maize in the United States, the predicted area increase is 19 million acres. For comparison, the total corn area in the United States is approximately 80 million acres. If the area expansion were to occur in less productive parts of the world, the land conversion would be even greater. For example, Brazil would require an area that is almost three times as large to derive the same amount of calories from maize. ${ }^{20}$ As shown in Table 9, exporting countries like the Unites States and Brazil have been more responsive to fluctuations in world price.

\section{Conclusions}

We have two basic goals with this analysis. The first is to demonstrate how weather-induced yield shocks can facilitate estimation of both supply and demand of agricultural commodities. In applying this idea to the available data we found it more practical to use yield shocks (deviations from quadratic time trends of output per land unit), mainly due to a weak instruments problem. This is stemming from the difficulty in predicting yields outside the United States. The second objective is to estimate elasticities for caloric energy from the world's most predominant food commodities. While the idea of using weather to identify demand is an old idea, it has rarely been applied, and to our knowledge has never been

\footnotetext{
${ }^{19}$ As pointed out above, not instrumenting the price can bias the results towards zero as outlined in the soybean rust example in the introduction.

${ }^{20}$ It should be noted that we are using average calories per acre, yet the correct measure would be the amount of calories obtained on the marginal land. These numbers should hence been seen as a first proxy.
} 
applied on a global scale. Our approach of using weather to identify supply is new, and we show this approach results in supply estimates that are far more elastic than those obtained using traditional methods.

Our model is simple. By aggregating crops and countries, we obscure the likely importance of many important factors, especially the imperfect substitutability of crops, transportation costs, tariffs, trade restrictions, and agricultural subsidies. But what the model lacks in complexity, it gains in transparency. We see these estimates as a complement to larger and more sophisticated computational models, wherein local supply and demand responses are either assumed or estimated individually, and transportation and trade restrictions are carefully accounted for. Our estimates provide a useful reality check for whether micro complexities add up to patterns that are observable in the aggregate data.

With this perspective in mind, we consider price and quantity predictions stemming from the rapid and largely policy-induced expansion of ethanol demand. The US ethanol policy has diverted (or will soon divert) approximately 5 percent of world caloric production into ethanol production. Since commodities are storable and the current ethanol production trend was largely anticipated since the Energy Policy Act of 2005, it is reasonable to expect that futures prices would have quickly incorporated the shift in demand, even though it has taken several years for ethanol production growth to be realized. Using our preferred estimated supply and demand elasticities, a shift of this magnitude would cause an estimated increase in price equal to 30 percent if none of the corn used for biofuel production can be recycled. If the distillers' left over grains from corn used in ethanol production is recycled as feed stock, the price increase would be scaled back accordingly. For example, if one third of the calories can be recovered as feed stock, the price increase would be lowered to 20 percent. Note, however, that this difference might easily be compensated by further anticipated growth in biofuel production. These predicted price increases are far smaller than those obtained using a SUR model that does not account for the endogeneity of prices, or from a model that accounts for the endogeneity of current prices in the demand equation but does not instrument futures prices in the supply equation. Our prediction is slightly larger than the USDA projected price increase made for corn in 2007, and would suggest that the ethanol subsidy had some role in the four-fold price increase, but by no means can account for all of it.

It is surprising that research in agricultural economics has not made greater use of weather-based instruments. One possible reason is the difficulty in linking weather variables to agricultural outcomes, like crop yields. We have circumvented this difficulty by 
summing local yield deviations from trend. In theory such deviations might be part of the supply response function and therefore endogenous; in practice; however, this appears to be a small issue. Nevertheless, use of weather variables instead of yield shocks may be a promising direction for future research. To make such an approach viable will require rich weather data and a parsimonious model linking weather to yield. Yield shocks attributable to fine scale weather data in the United States shows a correlation coefficient of 0.71 with our baseline deviations from trends. This suggests a both powerful instrument and limited endogenous yield response in the United States. However, the likely imprecision of fine-scaled weather data outside the United States makes it more difficult to obtain powerful instruments in other countries. Some of our difficulty may also result from different agronomic processes in wheat and rice production, which are more prevalent outside the United States, as compared to corn and soybeans, where the United States is dominant producer. While our results using weather-based yield shocks are comparable to the ones we obtain in our baseline model, the results are not very robust.

Our analysis suggests factors besides the US ethanol policy likely contributed strongly to the rapid price rise between 2006 and 2008. These factors may include rapid growth in the demand for basic calories from emerging economies like China. This demand growth has accelerated through demand for meat and other animal-based foods, which are highly income elastic. While population doubled in China between 1961 and 2006, meat consumption grew 33-fold (FAO), and comprised a little less than a third of the world's meat consumption in 2006. Meat requires between 5-10 times the agricultural area to obtain the same amount of calories as a vegetarian diet. This demand growth may resume as the world economy recovers from the financial crisis and subsequent recession of 2009. Another reason for the fourfold price increase is a decrease in supply due to detrimental weather, such as prolonged drought in Australia, coupled with low worldwide inventories. Also, the United States is the largest exporter of agricultural commodities and many commodity markets are denominated in US dollars. The devaluation of the dollar therefore increased the price for commodities in dollars. Some have argued that the commodity price boom, much like earlier housing and stock market booms, were due to a speculative bubble. However, recorded inventories of all major commodities declined throughout most the boom, and it is difficult to reconcile a bubble with an absence of inventory growth. Finally, prices, particularly those for rice, were influenced by temporary export bans in Vietnam and India, as well as speculation led by Thailand about a possible formation of rice exporters' cartel. Since the Fall of 2008, prices have fallen precipitously, at least partly due to a large inward shift in demand stemming 
from the global economic slowdown.

Because we find supply response occurs mainly through land use rather than through output per unit area, our results likely have implications for the carbon balance of land or commodity-based related policies. Ethanol subsidies or carbon offsets derived from limiting agricultural production in certain targeted areas will raise prices and thereby cause greater expansion of cropland in other locations. Econometric estimates of full carbon balance effects would require much more detail on the particular land-use transitions and where they occur. Substitution of rangeland for cropland would likely have less of an influence that substitution of rainforest for cropland. It is possible, however, that land transitions from rangeland to cropland facilitate transitions of forest to rangeland. While these calculations are beyond the scope of this article, the fact that the United States and especially Brazil have the largest estimated supply elasticities suggests these effects could be substantial. 


\section{References}

Askari, Hossein and John Thomas Cummings, "Estimating Agricultural Supply Response with the Nerlove Model: A Survey," International Economic Review, June 1977, 18 (2), 257-292.

Barr, Kanlaya J., Bruce A. Babcock, Miguel Carriquiry, Andre Nasser, and Leila Harfuch, "Agricultural Land Elasticities in the United States and Brazil," Working Paper 10-WP 505. Iowa State University., February 2010.

Bento, Antonio M., Lawrence H. Goulder, Mark R. Jacobsen, and Roger H. von Haefen, "Distributional and Efficiency Impacts of Increased US Gasoline Taxes," American Economic Review, June 2009, 99 (3), 667-699.

Bobenrieth H., Eugenio S. A., Juan R. A. Bobenrieth H., and Brian D. Wright, "A Commodity Price Process with a Unique Continuous Invariant Distribution Having Infinite Mean," Econometrica, May 2002, 70 (3), 1213-1219.

Burke, Marshall B., Edward Miguel, Shanker Satyanath, John A. Dykema, and David B. Lobell, "Warming increases the risk of civil war in Africa," Proceedings of the National Academy of Sciences, November 23 2009, 106 (49), 2067020674.

Cassman, Kenneth G., "Ecological intensification of cereal production systems: Yield potential, soil quality, and precision agriculture," Proceedings of the National Academy of Sciences, May 1999, 96, 59525959.

Holland, Stephen P., Jonathan E. Hughes, and Christopher R. Knittel, "Greenhouse Gas Reductions under Low Carbon Fuel Standards?," American Economic Journal: Economic Policy, February 2009, 1 (1), 106-146.

IPCC, Climate Change 200\%: Synthesis Report, International Panel on Climate Change, 2007.

Li, Shanjun, Christopher Timmins, and Roger H. von Haefen, "How Do Gasoline Prices Affect Fleet Fuel Economy?," American Economic Journal: Economic Policy, August 2009, 1 (2), 113137.

Miguel, Edward, Shanker Satyanath, and Ernest Sergenti, "Economic Shocks and Civil Conflict: An Instrumental Variables Approach," Journal of Political Economy, August 2004, 112 (4), 725-753.

Mitchell, Timothy D. and Philip D. Jones, "An improved method of constructing a database of monthly climate observations and associated high-resolution grids," International Journal of Climatology, May 2005, 25 (6), 693-712. 
Monfreda, Chad, Navin Ramankutty, and Jonathan A. Foley, "Farming the planet:2. Geographic distribution of crop areas, yields, physiological types, and net primary production in the year 2000," Global Biogeochemical Cycles, 2008, 22, 1-19.

Nelson, Charles R. and Richard Startz, "Further Results on the Exact Small Sample Properties of the Instrumental Variable Estimator," Econometrica, July 1990, 58 (4), 967-976.

Nerlove, Marc, The dynamics of supply; estimation of farmer's response to price, Baltimore: Johns Hopkins University Press, 1958.

Rajagopal, D., E. Sexton, D. Roland-Holst, and D. Zilberman, "Challenge of biofuel: filling the tank without emptying the stomach?," Environmental Research Letters, October-December 2007, $2(4), 9$.

Roberts, Michael J. and Nigel Key, A Comprehensive Assessment of the Role of Risk in U.S. Agriculture, Boston: Kluwer Academic Publishers,

and Wolfram Schlenker, "World Supply and Demand of Food Commodity Calories," American Journal of Agricultural Economics (Proceedings of the Agricultural \&6 Applied Economics Association Sessions at the 2009 ASSA Meeting in San Francisco), December 2009, 91 (5), 1235-1242.

, Nigel Key, and Erik ODonoghue, "Estimating the Extent of Moral Hazard in Crop Insurance Using Administrative Data," Review of Agricultural Economics, Fall 2006, 28 (3), 381390.

Sacks, W. J., D. Deryng, J.A. Foley, and N. Ramankutty, "Crop planting dates: An analysis of global patterns. Global Ecology and Biogeography.," Memorandum, 2010.

Scheinkman, Josè A. and Jack Schechtman, "A Simple Competitive Model with Production and Storage," Review of Economic Studies, July 1983, 50 (3), 427-441.

Schlenker, Wolfram and Michael J. Roberts, "Nonlinear Temperature Effects Indicate Severe Damages to U.S. Crop Yields under Climate Change," Proceedings of the National Academy of Sciences, September 15 2009, 106 (37), 15594-15598.

Searchinger, Timothy, Ralph Heimlich, R. A. Houghton, Fengxia Dong, Amani Elobeid, Jacinto Fabiosa, Simla Tokgoz, Dermot Hayes, and Tun-Hsiang Yu, "Use of U.S. Croplands for Biofuels Increases Greenhouse Gases Through Emissions from Land-Use Change," Science, 7 February 2008 2008, 319 (5867), 1238-1240.

Williamson, Lucille and Paul Williamson, "What We Eat," Journal of Farm Economics, August 1942, 24 (3), 698-703.

Wright, Philip G., The tariff on animal and vegetable oils, New York: MacMillan, 1928. 
Figure 1: Production and Consumption of Calories from Maize, Wheat, Rice, and Soybeans
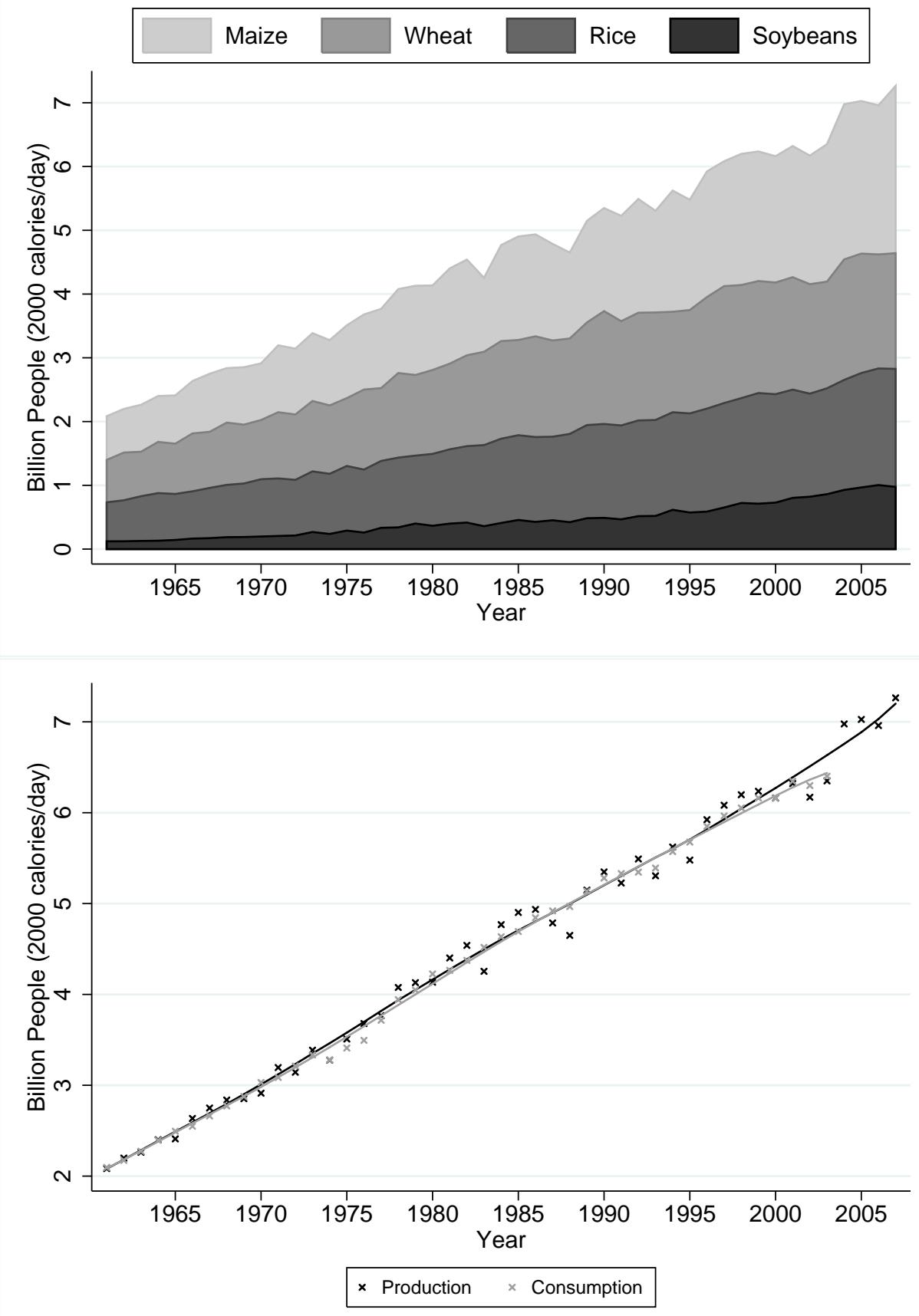

Notes: Top panel displays world production of calories from maize, wheat, rice, and soybeans for 19612007. The y-axis are the number of people who could be fed on a 2000 calories/day diet. Bottom level displays production as well as consumption of the same four commodities. A locally weighted regression line (bandwidth of 10 year) is added. 
Figure 2: Scatter Plots of Annual Yields (Countries with more than 1 Percent of World Production)
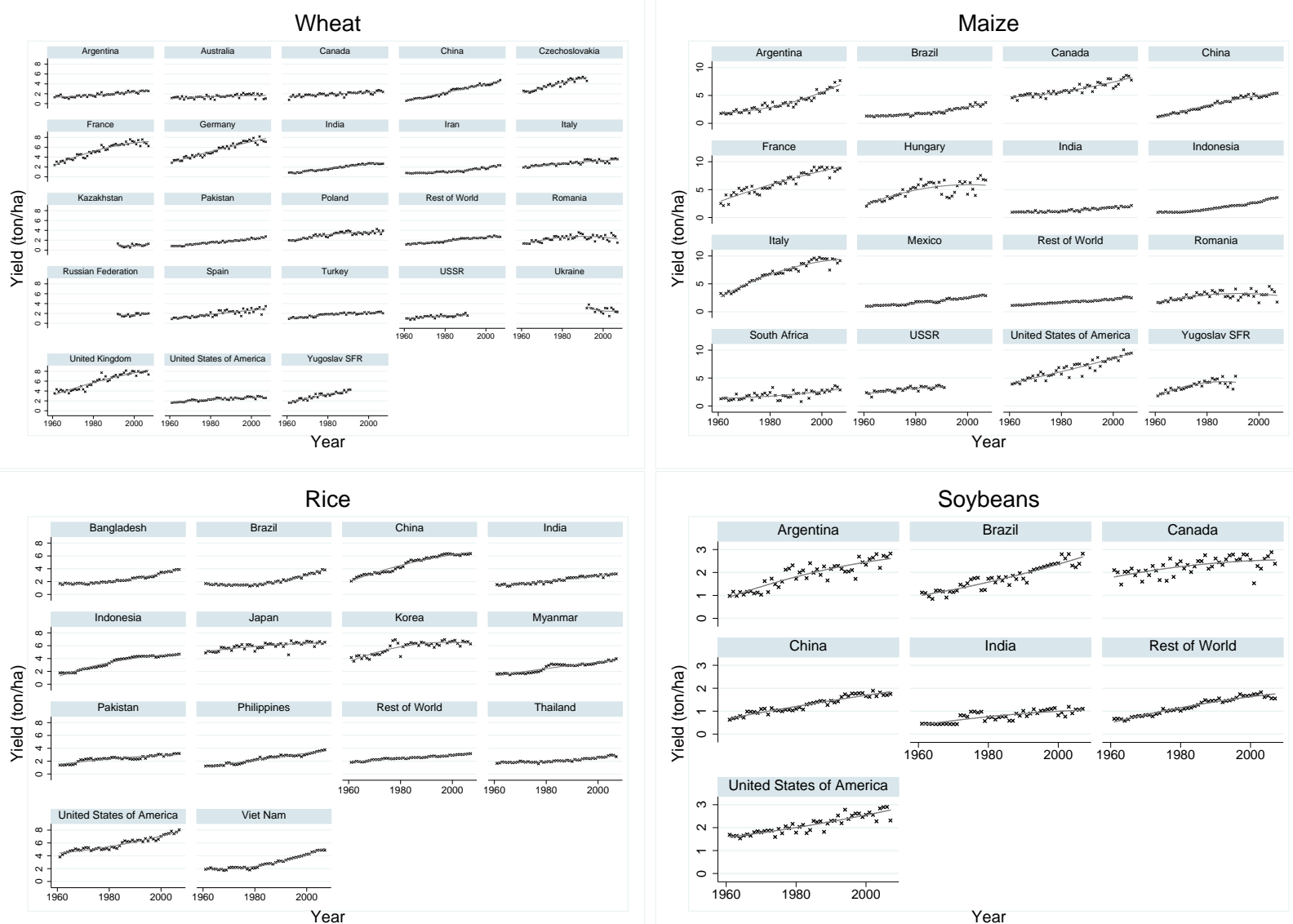

Notes: Scatter plots of yields in each country against time. A quadratic time trend is added as a solid line. Figure shows all countries that produce on average more than 1 percent of world production. All other countries are lumped together as "Rest of World". 
Figure 3: Annual Jackknifed Yield Residuals (Countries with more than 1 Percent of World Production)
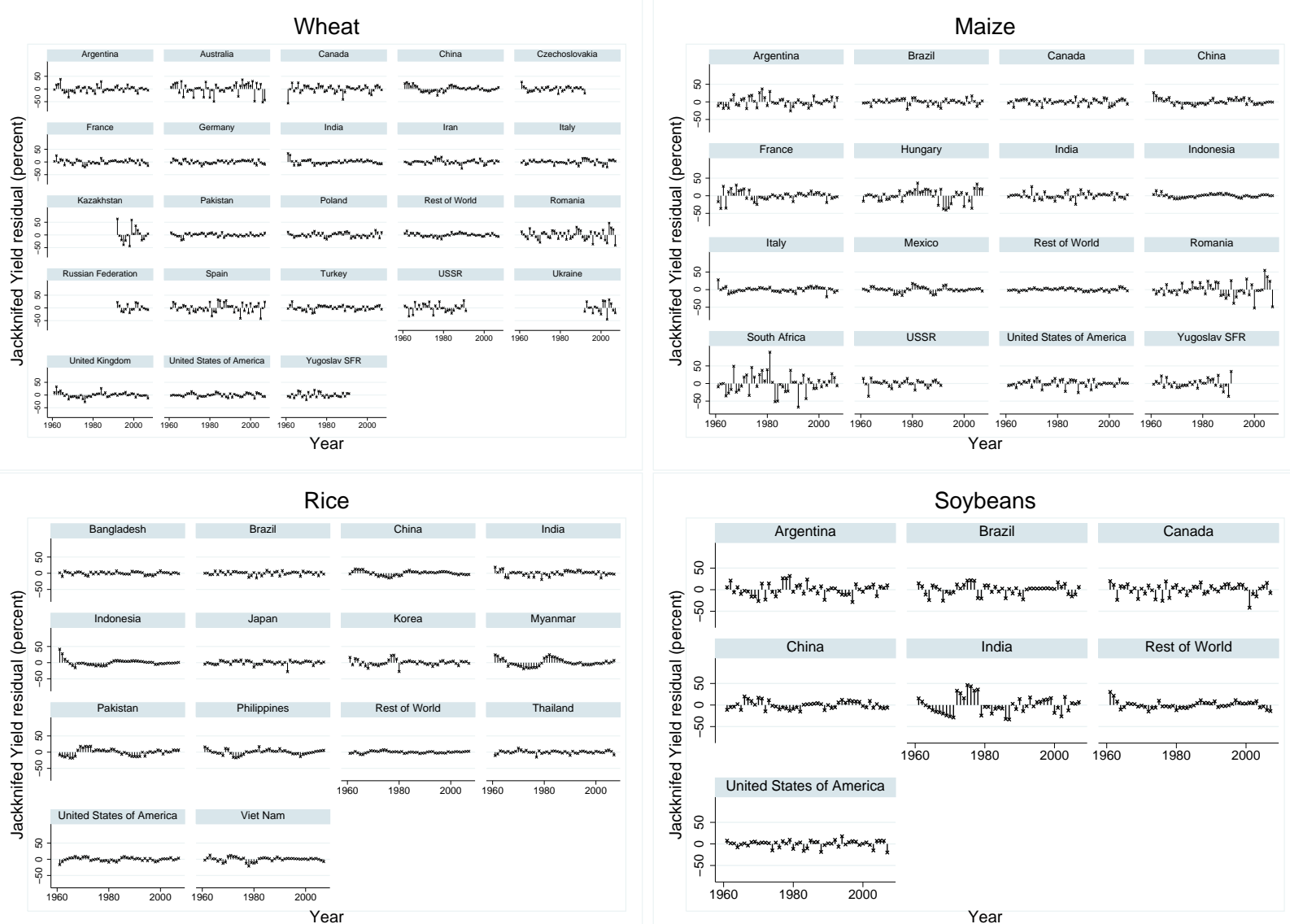

Notes: Scatter plots of jackknifed yield residuals, i.e., the residual is estimated by excluding the observation in question. Figure shows all countries that produce on average more than 1 percent of world production. All other countries are lumped together as "Rest of World". 
Figure 4: Correlation of Residuals of Two Largest Producers
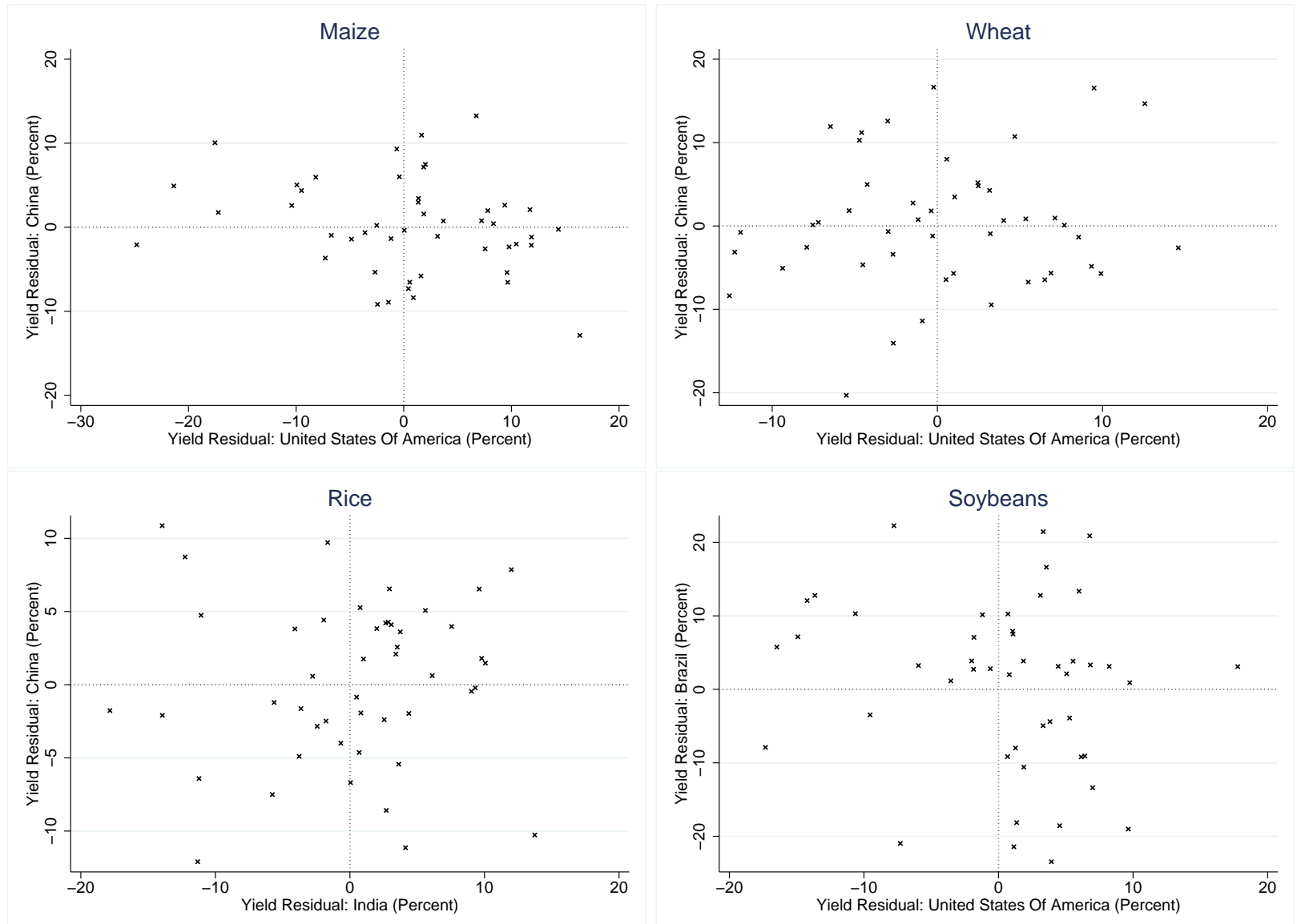

Notes: Figure shows scatter plots of yield residuals (deviations from a quadratic trend) of the two largest producers of each crop. The correlation coefficients are -0.24 for maize, 0.12 for wheat, 0.05 for rice, and -0.18 for soybeans. 
Figure 5: World Growing Area of Crops

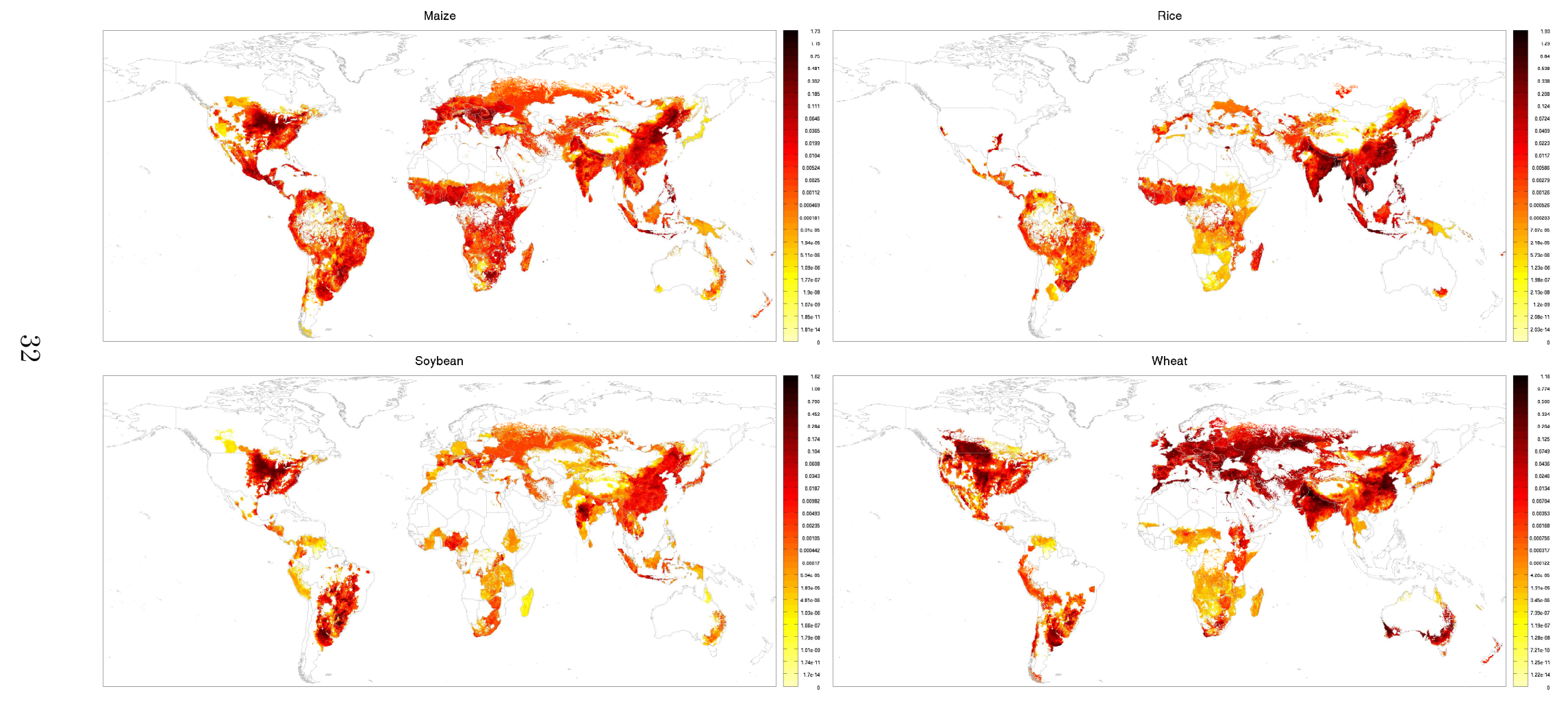

Notes: Panels displays the fraction of each grid cell that is used to grow a crop. A fraction greater than one indicates double cropping. 
Figure 6: Price and Caloric Shocks
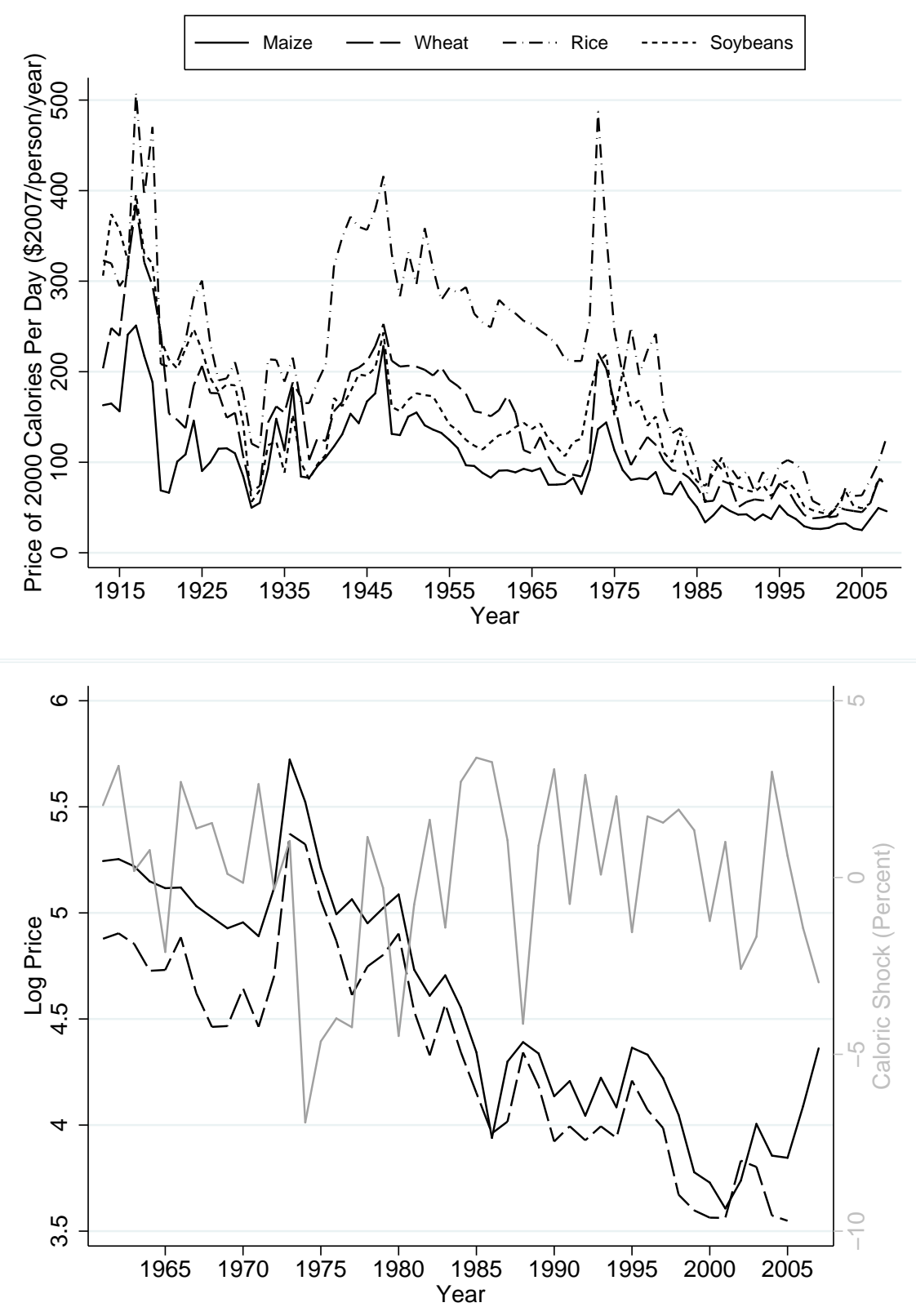

Notes: Top panel displays real annual cost of maize, wheat, rice, and soybeans in 2007 dollars for a 2000 calories per day diet using USDA's December price series. Overall, prices show a downward trend, and the recent spike in food prices in small in absolute terms. However, the spike is large in term of relative increase (threefold increase).

The bottom panel displays log price on the left axis in black and caloric shocks (as percent deviation from production trend) on the right axis in grey for the years 1961-2007. Production-weighted December prices of maize, wheat, rice and soybeans are shown as solid black line, while production-weighted futures prices at delivery (December for maize, November for soybeans, and September for wheat) are shown as dashed line. Shocks are deviations from country-specific yield trends for the same four commodities. 
Figure 7: US Share of World Production

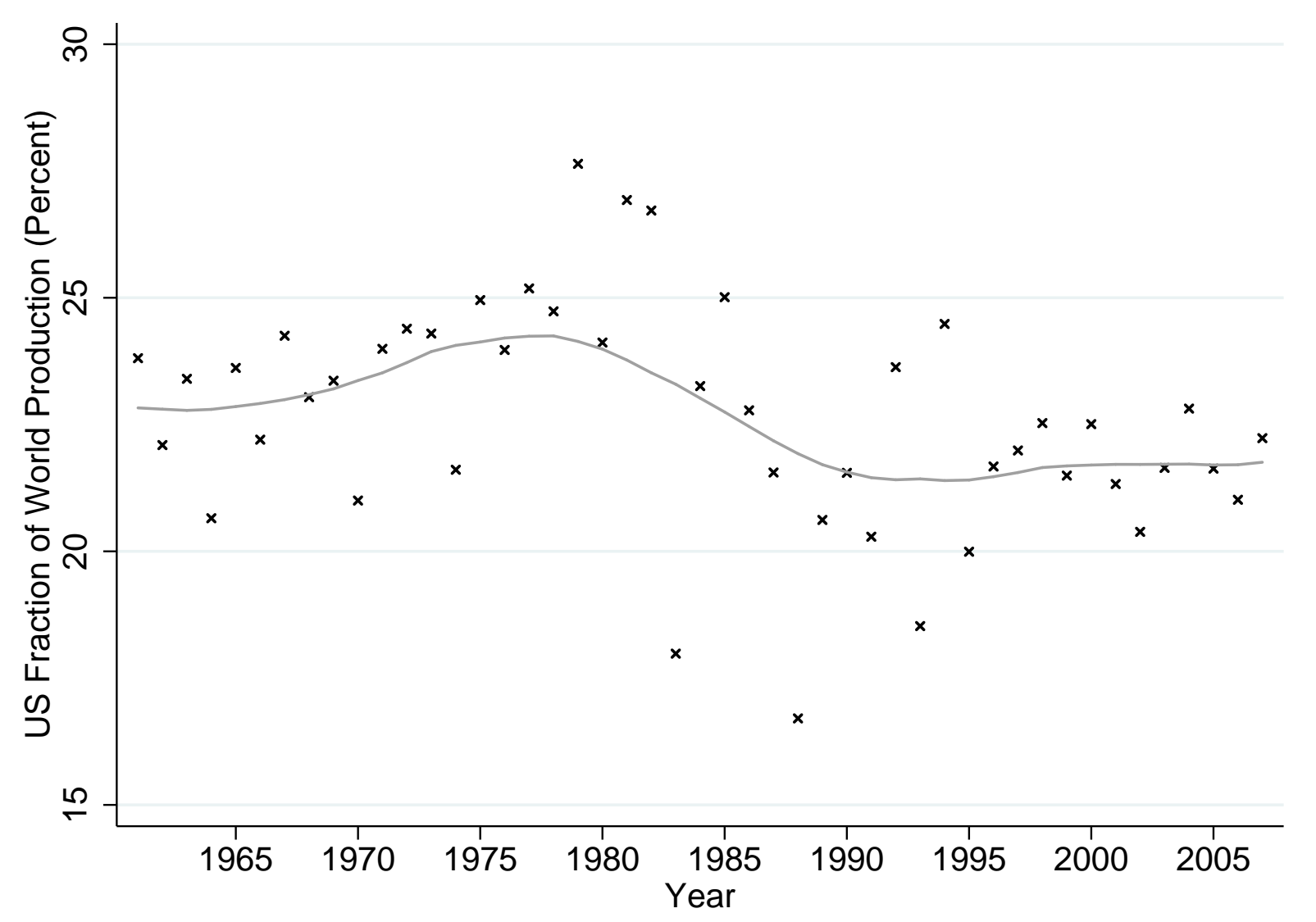

Notes: Graph displays the percent of world wide caloric production from maize, wheat, rice and soybeans that is produced in the United State. Yearly observations are shown as crosses and a locally weighted regression with a bandwidth of 10 years is added in grey. 
Figure 8: US Ethanol Production Capacity Over Time and as Share of World Capacity

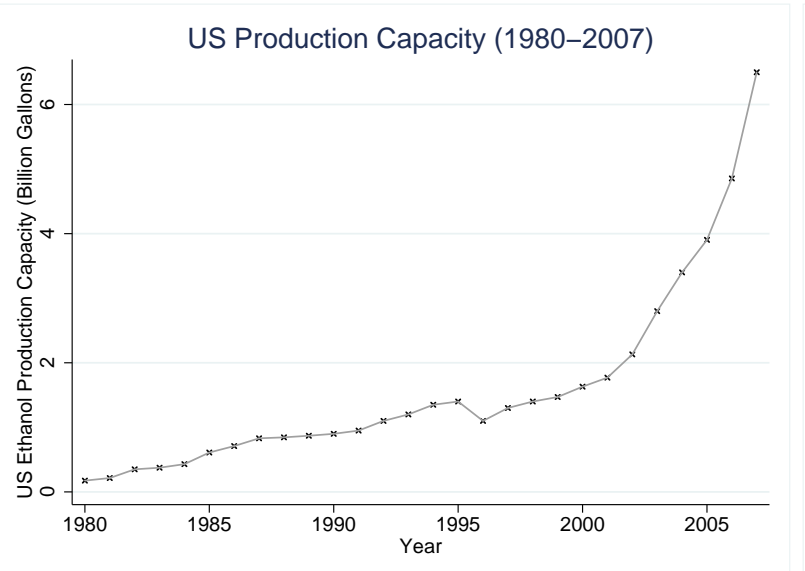

Share of Global Capacity in 2006

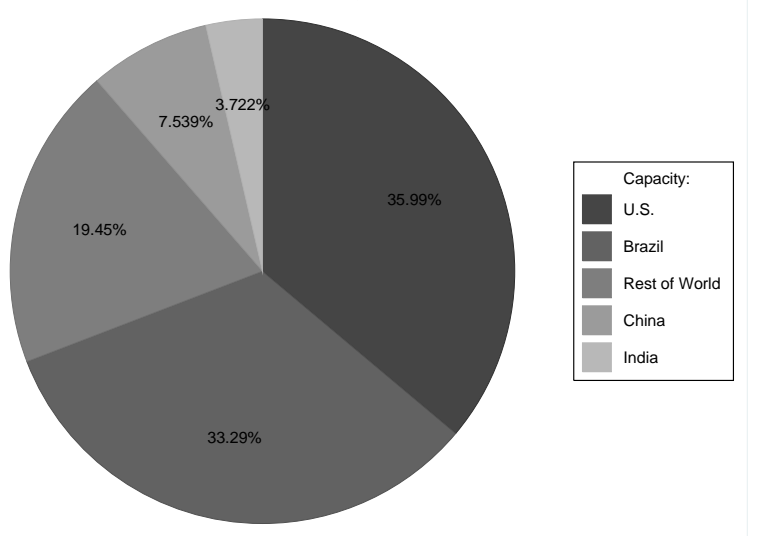

Notes: Left panel shows ethanol production capacity in billion gallons 1980-2007. The right panel shows the US share of global capacity in 2006 as well as producers with next biggest market shares. 
Figure 9: Contrasting Caloric Shocks: Deviations from Trend versus Weather Induced Residuals

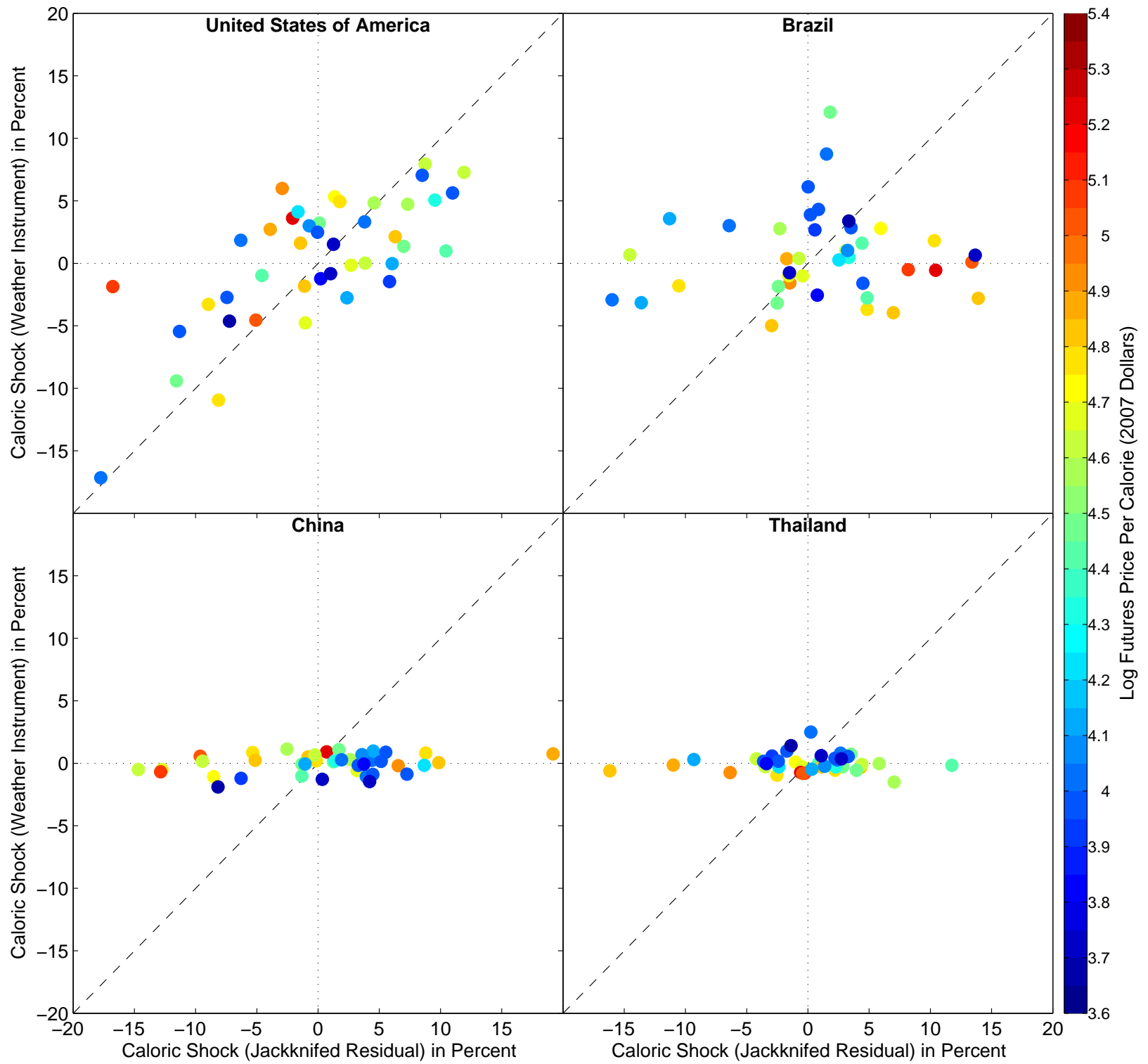

Notes: Figure shows scatter plots of caloric chocks for four countries. The x-axis shows caloric shocks using yield deviations from a quadratic time trend. The y-axis uses yield shocks that are obtained from regressing yields on weather measures. The scatter plots are color coded by the futures price (traded in the previous year). 
Table 1: Countries with Share of World Production Greater than 1 Percent

\begin{tabular}{|c|c|c|c|}
\hline 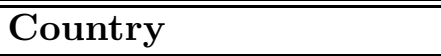 & Share & Country & Share \\
\hline \multicolumn{2}{|l|}{ Wheat } & \multicolumn{2}{|l|}{ Maize } \\
\hline USSR & 21.23 & United States of America & 42.00 \\
\hline China & 14.05 & China & 15.66 \\
\hline United States of America & 12.07 & Brazil & 5.21 \\
\hline India & 8.53 & USSR & 3.52 \\
\hline Russian Federation & 6.86 & Mexico & 3.01 \\
\hline France & 5.33 & Yugoslav SFR & 2.47 \\
\hline Canada & 4.81 & Argentina & 2.35 \\
\hline Turkey & 3.48 & France & 2.32 \\
\hline Australia & 3.13 & Romania & 2.15 \\
\hline Germany & 2.89 & South Africa & 2.01 \\
\hline Ukraine & 2.69 & India & 1.91 \\
\hline Pakistan & 2.49 & Italy & 1.54 \\
\hline Argentina & 2.23 & Hungary & 1.41 \\
\hline Italy & 2.06 & Indonesia & 1.26 \\
\hline United Kingdom & 2.01 & Canada & 1.15 \\
\hline Kazakhstan & 1.87 & Rest of World & 14.07 \\
\hline Iran, Islamic Republic of & 1.54 & & \\
\hline Poland & 1.38 & & \\
\hline Yugoslav SFR & 1.29 & & \\
\hline Romania & 1.27 & & \\
\hline Spain & 1.16 & & \\
\hline Czechoslovakia & 1.05 & & \\
\hline Rest of World & 12.12 & & \\
\hline \multicolumn{2}{|l|}{ Rice } & \multicolumn{2}{|l|}{ Soybeans } \\
\hline China & 34.44 & United States of America & 56.73 \\
\hline India & 20.64 & Brazil & 14.43 \\
\hline Indonesia & 7.50 & China & 13.05 \\
\hline Bangladesh & 5.48 & Argentina & 6.62 \\
\hline Thailand & 4.27 & India & 1.63 \\
\hline Vietnam & 3.97 & Canada & 1.04 \\
\hline Japan & 3.67 & Rest of World & 6.49 \\
\hline Myanmar & 3.12 & & \\
\hline Brazil & 2.08 & & \\
\hline Philippines & 1.87 & & \\
\hline Korea, Republic of & 1.59 & & \\
\hline United States of America & 1.44 & & \\
\hline Pakistan & 1.07 & & \\
\hline Rest of World & 8.86 & & \\
\hline
\end{tabular}

Notes: Table reports all countries with an average yearly share of world production (19612007) above one percent for each crop. All other countries are lumped together as "Rest of World". 
Table 2: Descriptive Statistics

\begin{tabular}{|c|c|c|c|c|c|c|}
\hline Variable & Unit & Mean & Std. & Dev. & Min & Max \\
\hline Year & & 1982 & & 12.56 & 1961 & 2003 \\
\hline Caloric Production & billion people & 4.32 & & 1.34 & 2.08 & 6.35 \\
\hline Caloric Storage & million people & 15.9 & & 118 & -317 & 210 \\
\hline Caloric Stock & million people & 982 & & 339 & 445 & 1564 \\
\hline Caloric Shock - Dev. from Linear Trend & million people & 2.97 & & 104 & -226 & 175 \\
\hline Caloric Shock - Dev. from Quadratic Trend & million people & 4.67 & & 107 & -240 & 159 \\
\hline Caloric Shock - Weather Inst. Linear Trend & million people & -2.29 & & 65 & -219 & 105 \\
\hline Caloric Shock - Weather Inst. Quadratic Trend & million people & 0.15 & & 60 & -218 & 92 \\
\hline Caloric Price - Futures at Delivery & US\$2007 per year & 89.43 & & 42.96 & 35.25 & 215.44 \\
\hline Caloric Price - Futures one Year Before & US $\$ 2007$ per year & 87.98 & & 37.24 & 38.62 & 189.60 \\
\hline Caloric Price - Dec. USDA Prices & US $\$ 2007$ per year & 117.29 & & 60.95 & 36.85 & 305.76 \\
\hline Log Caloric Supply & Log billion people & 1.412 & & 0.337 & 0.734 & 1.849 \\
\hline Log Caloric Demand & Log billion people & 4.060 & & 1.261 & 1.495 & 5.775 \\
\hline Log Caloric Price - Futures at Delivery & Log US\$2007 per year & 4.385 & & 0.474 & 3.563 & 5.373 \\
\hline Log Caloric Price - Futures one Year Before & Log US\$2007 per year & 4.388 & & 0.430 & 3.654 & 5.245 \\
\hline Log Caloric Price - Dec. USDA Prices & Log US $\$ 2007$ per year & 4.628 & & 0.540 & 3.607 & 5.723 \\
\hline
\end{tabular}

Notes: Descriptive Statistics of the 43 annual observations used in the demand/supply equation. Quantities are in the number of people that could be fed on a 2000 calories a day diet. Prices are the annual cost of a daily diet of 2000 calories in US $\$ 2007$. 
Table 3: Demand and Supply Elasticities of Calories using Jackknifed Yield Residuals

\begin{tabular}{|c|c|c|c|c|c|c|}
\hline & \multicolumn{6}{|c|}{ Model } \\
\hline & 2SLS & 3SLS & 2SLS & 3SLS & 2SLS & 3SLS \\
\hline $\begin{array}{l}\text { Demand Elasticity } \\
\text { (s.e.) }\end{array}$ & $\begin{array}{c}-0.0505^{* * *} \\
(0.0190)\end{array}$ & $\begin{array}{c}-0.0554^{* * *} \\
(0.0167)\end{array}$ & $\begin{array}{c}-0.0641^{* *} \\
(0.0243)\end{array}$ & $\begin{array}{c}-0.0797^{* * *} \\
(0.0215)\end{array}$ & $\begin{array}{c}-0.0668^{* * *} \\
(0.0241)\end{array}$ & $\begin{array}{c}-0.0634^{* * *} \\
(0.0226)\end{array}$ \\
\hline $\begin{array}{l}\text { Supply Elasticity } \\
\text { (s.e.) }\end{array}$ & $\begin{array}{c}0.1165^{* * *} \\
(0.0286)\end{array}$ & $\begin{array}{c}0.1337^{* * *} \\
(0.0241)\end{array}$ & $\begin{array}{c}0.0826^{* * *} \\
(0.0217)\end{array}$ & $\begin{array}{c}0.0951^{* * *} \\
(0.0189)\end{array}$ & $\begin{array}{c}0.0957^{* * *} \\
(0.0208)\end{array}$ & $\begin{array}{c}0.0979^{* * *} \\
(0.0189)\end{array}$ \\
\hline \multirow[t]{2}{*}{$\begin{array}{l}\text { Price Increase } \\
95 \% \text { Conf. Int. }\end{array}$} & $\begin{array}{c}31.41 \\
(21.32,50.14) \\
\end{array}$ & $\begin{array}{c}27.01 \\
(20.69,36.62) \\
\end{array}$ & $\begin{array}{c}36.10 \\
(23.75,60.31) \\
\end{array}$ & $\begin{array}{c}29.31 \\
(22.01,40.80) \\
\end{array}$ & $\begin{array}{c}32.14 \\
(22.23,50.00) \\
\end{array}$ & $\begin{array}{c}32.16 \\
(22.79,48.40) \\
\end{array}$ \\
\hline & \multicolumn{6}{|c|}{ Demand } \\
\hline Price $p_{t}$ & $\begin{array}{c}-5.05 \mathrm{e}-02^{* * *} \\
(1.90 \mathrm{e}-02)\end{array}$ & $\begin{array}{c}-5.54 \mathrm{e}-02^{* * *} \\
(1.67 \mathrm{e}-02)\end{array}$ & $\begin{array}{c}-6.41 \mathrm{e}-02^{* *} \\
(2.43 \mathrm{e}-02)\end{array}$ & $\begin{array}{c}-7.97 \mathrm{e}-02^{* * *} \\
(2.15 \mathrm{e}-02)\end{array}$ & $\begin{array}{c}-6.68 \mathrm{e}-02^{* * *} \\
(2.41 \mathrm{e}-02)\end{array}$ & $\begin{array}{c}-6.34 \mathrm{e}-02^{* * *} \\
(2.26 \mathrm{e}-02)\end{array}$ \\
\hline Time Trend & $\begin{array}{c}4.26 \mathrm{e}-02^{* * *} \\
(8.32 \mathrm{e}-04)\end{array}$ & $\begin{array}{c}4.26 \mathrm{e}-02^{* * *} \\
(8.57 \mathrm{e}-04)\end{array}$ & $\begin{array}{c}4.56 \mathrm{e}-02^{* * *} \\
(2.50 \mathrm{e}-03)\end{array}$ & $\begin{array}{c}4.77 \mathrm{e}-02^{* * * *} \\
(2.81 \mathrm{e}-03)\end{array}$ & $\begin{array}{c}4.69 \mathrm{e}-02^{* * *} \\
(3.03 \mathrm{e}-03)\end{array}$ & $\begin{array}{c}4.77 \mathrm{e}-02^{* * *} \\
(3.44 \mathrm{e}-03)\end{array}$ \\
\hline Time Trend ${ }^{2}$ & $\begin{array}{c}-4.18 \mathrm{e}-04^{* * *} \\
(2.34 \mathrm{e}-05)\end{array}$ & $\begin{array}{c}-4.23 \mathrm{e}-04^{* * *} \\
(2.28 \mathrm{e}-05)\end{array}$ & $\begin{array}{c}-6.12 \mathrm{e}-04^{* * *} \\
(1.53 \mathrm{e}-04)\end{array}$ & $\begin{array}{c}-7.34 \mathrm{e}-04^{* * *} \\
(1.63 \mathrm{e}-04)\end{array}$ & $\begin{array}{c}-6.74 \mathrm{e}-04^{* * *} \\
(1.77 \mathrm{e}-04)\end{array}$ & $\begin{array}{c}-7.07 \mathrm{e}-04^{* * *} \\
(1.93 \mathrm{e}-04)\end{array}$ \\
\hline \multirow[t]{2}{*}{ Time Trend ${ }^{3}$} & & & $\begin{array}{c}2.93 \mathrm{e}-06 \\
(2.26 \mathrm{e}-06)\end{array}$ & $\begin{array}{l}4.56 \mathrm{e}-06^{*} \\
(2.37 \mathrm{e}-06)\end{array}$ & $\begin{array}{c}3.78 \mathrm{e}-06 \\
(2.57 \mathrm{e}-06)\end{array}$ & $\begin{array}{l}4.23 \mathrm{e}-06 \\
(2.74 \mathrm{e}-06)\end{array}$ \\
\hline & \multicolumn{6}{|c|}{ Supply } \\
\hline $\mathbb{E}\left[\left.p_{t}\right|_{t-1}\right]$ & $\begin{array}{c}1.17 \mathrm{e}-01^{* * * *} \\
(2.86 \mathrm{e}-02)\end{array}$ & $\begin{array}{c}1.34 \mathrm{e}-01^{* * *} \\
(2.41 \mathrm{e}-02)\end{array}$ & $\begin{array}{c}8.26 \mathrm{e}-02^{* * *} \\
(2.17 \mathrm{e}-02)\end{array}$ & $\begin{array}{c}9.51 \mathrm{e}-02^{* * *} \\
(1.89 \mathrm{e}-02)\end{array}$ & $\begin{array}{c}9.57 \mathrm{e}-02^{* * *} \\
(2.08 \mathrm{e}-02)\end{array}$ & $\begin{array}{c}9.79 \mathrm{e}-02^{* * *} \\
(1.89 \mathrm{e}-02)\end{array}$ \\
\hline Shock $\omega_{t}$ & $\begin{array}{c}2.46 \mathrm{e}-01^{* * *} \\
(3.37 \mathrm{e}-02)\end{array}$ & $\begin{array}{c}2.62 \mathrm{e}-01^{* * *} \\
(2.94 \mathrm{e}-02)\end{array}$ & $\begin{array}{c}2.61 \mathrm{e}-01^{* * *} \\
(2.65 \mathrm{e}-02)\end{array}$ & $\begin{array}{c}2.72 \mathrm{e}-01^{* * *} \\
(2.38 \mathrm{e}-02)\end{array}$ & $\begin{array}{c}2.71 \mathrm{e}-01^{* * *} \\
(2.56 \mathrm{e}-02)\end{array}$ & $\begin{array}{c}2.73 \mathrm{e}-01^{* * *} \\
(2.35 \mathrm{e}-02)\end{array}$ \\
\hline Time Trend & $\begin{array}{c}4.46 \mathrm{e}-02^{* * *} \\
(9.34 \mathrm{e}-04)\end{array}$ & $\begin{array}{c}4.46 \mathrm{e}-02^{* * *} \\
(8.74 \mathrm{e}-04)\end{array}$ & $\begin{array}{c}5.41 \mathrm{e}-02^{* * *} \\
(2.04 \mathrm{e}-03)\end{array}$ & $\begin{array}{c}5.40 \mathrm{e}-02^{* * *} \\
(1.89 \mathrm{e}-03)\end{array}$ & $\begin{array}{c}5.27 \mathrm{e}-02^{* * *} \\
(2.32 \mathrm{e}-03)\end{array}$ & $\begin{array}{c}5.26 \mathrm{e}-02^{* * *} \\
(2.14 \mathrm{e}-03)\end{array}$ \\
\hline Time Trend ${ }^{2}$ & $\begin{array}{c}-3.54 \mathrm{e}-04^{* * *} \\
(2.66 \mathrm{e}-05)\end{array}$ & $\begin{array}{c}-3.44 \mathrm{e}-04^{* * *} \\
(2.40 \mathrm{e}-05)\end{array}$ & $\begin{array}{c}-9.23 \mathrm{e}-04^{* * *} \\
(1.12 \mathrm{e}-04)\end{array}$ & $\begin{array}{c}-9.11 \mathrm{e}-04^{* * *} \\
(1.04 \mathrm{e}-04)\end{array}$ & $\begin{array}{c}-8.48 \mathrm{e}-04^{* * *} \\
(1.26 \mathrm{e}-04)\end{array}$ & $\begin{array}{c}-8.43 \mathrm{e}-04^{* * *} \\
(1.16 \mathrm{e}-04)\end{array}$ \\
\hline Time Trend ${ }^{3}$ & & & $\begin{array}{c}8.45 \mathrm{e}-06^{* * *} \\
(1.68 \mathrm{e}-06)\end{array}$ & $\begin{array}{c}8.37 \mathrm{e}-06^{* * *} \\
(1.55 \mathrm{e}-06) \\
\end{array}$ & $\begin{array}{c}7.52 \mathrm{e}-06^{* * *} \\
(1.81 \mathrm{e}-06) \\
\end{array}$ & $\begin{array}{c}7.46 \mathrm{e}-06^{* * *} \\
(1.68 \mathrm{e}-06) \\
\end{array}$ \\
\hline Observations & 42 & 42 & 42 & 42 & 41 & 41 \\
\hline Time Trend I & 2 & 2 & 3 & 3 & 3 & 3 \\
\hline Shock Lags K & 1 & 1 & 1 & 1 & 2 & 2 \\
\hline
\end{tabular}


Table 4: First-Stage Results for Demand and Supply Equation

\begin{tabular}{|c|c|c|c|c|c|c|}
\hline & \multicolumn{6}{|c|}{$\overline{\text { Model }}$} \\
\hline & 2SLS & 3SLS & 2SLS & 3SLS & 2SLS & 3SLS \\
\hline \multirow[b]{2}{*}{ Shock $\omega_{t}$} & \multicolumn{6}{|c|}{ Demand: First-Stage Instrumenting Price $p_{t}$} \\
\hline & $\begin{array}{c}-1.19 \mathrm{e}+00^{* * *} \\
(2.62 \mathrm{e}-01)\end{array}$ & $\begin{array}{c}-1.16 \mathrm{e}+00^{* * *} \\
(2.47 \mathrm{e}-01)\end{array}$ & $\begin{array}{c}-1.12 \mathrm{e}+00^{* * *} \\
(2.93 \mathrm{e}-01)\end{array}$ & $\begin{array}{c}-9.92 \mathrm{e}-01^{* * *} \\
(2.65 \mathrm{e}-01)\end{array}$ & $\begin{array}{c}-1.04 \mathrm{e}+00 * * * \\
(2.97 \mathrm{e}-01)\end{array}$ & $\begin{array}{c}-1.07 \mathrm{e}+00^{* * *} \\
(2.57 \mathrm{e}-01)\end{array}$ \\
\hline Shock $\omega_{t-1}$ & & & & & $\begin{array}{l}-3.99 \mathrm{e}-01 \\
(2.95 \mathrm{e}-01)\end{array}$ & $\begin{array}{l}-3.30 \mathrm{e}-01 \\
(2.02 \mathrm{e}-01)\end{array}$ \\
\hline \multirow[t]{2}{*}{ Time Trend } & $-8.43 \mathrm{e}-03$ & $-6.49 \mathrm{e}-03$ & $4.64 \mathrm{e}-03$ & $2.03 \mathrm{e}-02$ & $7.05 \mathrm{e}-04$ & $2.32 \mathrm{e}-02$ \\
\hline & $(9.73 \mathrm{e}-03)$ & $(1.01 \mathrm{e}-02)$ & $(2.64 \mathrm{e}-02)$ & $(2.84 \mathrm{e}-02)$ & $(3.22 \mathrm{e}-02)$ & $(3.28 \mathrm{e}-02)$ \\
\hline \multirow[t]{2}{*}{ Time Trend ${ }^{2}$} & $-5.49 \mathrm{e}-04^{* *}$ & $-5.88 \mathrm{e}-04^{* * *}$ & $-1.32 \mathrm{e}-03$ & $-2.10 \mathrm{e}-03$ & $-1.08 \mathrm{e}-03$ & $-2.12 \mathrm{e}-03$ \\
\hline & $(2.24 \mathrm{e}-04)$ & $(2.28 \mathrm{e}-04)$ & $(1.47 \mathrm{e}-03)$ & $(1.53 \mathrm{e}-03)$ & $(1.72 \mathrm{e}-03)$ & $(1.71 \mathrm{e}-03)$ \\
\hline \multirow[t]{3}{*}{ Time Trend ${ }^{3}$} & & & $1.22 \mathrm{e}-05$ & $2.32 \mathrm{e}-05$ & $8.68 \mathrm{e}-06$ & $2.26 \mathrm{e}-05$ \\
\hline & & & $(2.27 \mathrm{e}-05)$ & $(2.33 \mathrm{e}-05)$ & $(2.60 \mathrm{e}-05)$ & $(2.54 \mathrm{e}-05)$ \\
\hline & \multicolumn{6}{|c|}{ Supply: First-Stage Instrumenting Expected Price $\mathbb{E}\left[\left.p_{t}\right|_{t-1}\right]$} \\
\hline Shock $\omega_{t-1}$ & $\begin{array}{c}-8.60 \mathrm{e}-01^{* * *} \\
(2.14 \mathrm{e}-01)\end{array}$ & $\begin{array}{c}-7.52 \mathrm{e}-01^{* * *} \\
(1.91 \mathrm{e}-01)\end{array}$ & $\begin{array}{c}-9.18 \mathrm{e}-01^{* * *} \\
(2.26 \mathrm{e}-01)\end{array}$ & $\begin{array}{c}-8.17 \mathrm{e}-01^{* * *} \\
(1.98 \mathrm{e}-01)\end{array}$ & $\begin{array}{c}-8.33 \mathrm{e}-01^{* * *} \\
(2.20 \mathrm{e}-01)\end{array}$ & $\begin{array}{c}-8.45 \mathrm{e}-01^{* * *} \\
(1.96 \mathrm{e}-01)\end{array}$ \\
\hline Shock $\omega_{t-2}$ & & & & & $\begin{array}{l}-3.53 \mathrm{e}-01 \\
(2.21 \mathrm{e}-01)\end{array}$ & $\begin{array}{c}-3.41 \mathrm{e}-01^{*} \\
(1.89 \mathrm{e}-01)\end{array}$ \\
\hline Shock $\omega_{t}$ & $\begin{array}{c}-6.10 \mathrm{e}-01^{* * *} \\
(2.10 \mathrm{e}-01)\end{array}$ & $\begin{array}{c}-6.35 \mathrm{e}-01^{* * *} \\
(1.97 \mathrm{e}-01)\end{array}$ & $\begin{array}{c}-6.82 \mathrm{e}-01^{* * *} \\
(2.27 \mathrm{e}-01)\end{array}$ & $\begin{array}{c}-6.75 \mathrm{e}-01^{* * *} \\
(2.09 \mathrm{e}-01)\end{array}$ & $\begin{array}{c}-6.39 \mathrm{e}-01^{* * *} \\
(2.20 \mathrm{e}-01)\end{array}$ & $\begin{array}{c}-6.45 \mathrm{e}-01^{* * *} \\
(1.99 \mathrm{e}-01)\end{array}$ \\
\hline \multirow[t]{2}{*}{ Time Trend } & $-1.04 \mathrm{e}-02$ & $-9.64 \mathrm{e}-03$ & $-3.01 \mathrm{e}-02$ & $-2.54 \mathrm{e}-02$ & $-2.14 \mathrm{e}-02$ & $-2.17 \mathrm{e}-02$ \\
\hline & $(8.15 \mathrm{e}-03)$ & $(7.64 \mathrm{e}-03)$ & $(2.46 \mathrm{e}-02)$ & $(2.26 \mathrm{e}-02)$ & $(2.77 \mathrm{e}-02)$ & $(2.51 \mathrm{e}-02)$ \\
\hline \multirow[t]{2}{*}{ Time Trend $^{2}$} & $-4.39 \mathrm{e}-04^{* *}$ & $-4.57 \mathrm{e}-04^{* * *}$ & $6.72 \mathrm{e}-04$ & $4.25 \mathrm{e}-04$ & $2.55 \mathrm{e}-04$ & $2.76 \mathrm{e}-04$ \\
\hline & $(1.85 \mathrm{e}-04)$ & $(1.73 \mathrm{e}-04)$ & $(1.32 \mathrm{e}-03)$ & $(1.21 \mathrm{e}-03)$ & $(1.43 \mathrm{e}-03)$ & $(1.30 \mathrm{e}-03)$ \\
\hline \multirow[t]{2}{*}{ Time Trend ${ }^{3}$} & & & $-1.69 \mathrm{e}-05$ & $-1.34 \mathrm{e}-05$ & $-1.07 \mathrm{e}-05$ & $-1.11 \mathrm{e}-05$ \\
\hline & & & $(1.99 \mathrm{e}-05)$ & $(1.83 \mathrm{e}-05)$ & $(2.10 \mathrm{e}-05)$ & $(1.91 \mathrm{e}-05)$ \\
\hline Observations & $\overline{42}$ & $\overline{42}$ & 42 & 42 & 41 & 41 \\
\hline Time Trend I & 2 & 2 & 3 & 3 & 3 & 3 \\
\hline Shock Lags K & 1 & 1 & 1 & 1 & 2 & 2 \\
\hline
\end{tabular}

Notes: Table displays the first stage regressions for the results in Table 3. 
Table 5: First-Stage Results Separating Maize/Soybeans and Rice/Wheat Shocks

\begin{tabular}{|c|c|c|c|c|c|c|}
\hline & \multicolumn{6}{|c|}{$\overline{\text { Model }}$} \\
\hline & 2SLS & 3SLS & 2SLS & 3SLS & 2SLS & 3SLS \\
\hline \multirow[b]{2}{*}{ Shock $\omega_{t, M S}$} & \multicolumn{6}{|c|}{ "Demand: First-Stage Instrumenting Price $p_{t}$} \\
\hline & $\begin{array}{c}-1.14 \mathrm{e}+00^{* *} \\
(4.71 \mathrm{e}-01)\end{array}$ & $\begin{array}{c}-1.18 \mathrm{e}+00^{* * *} \\
(4.03 \mathrm{e}-01)\end{array}$ & $\begin{array}{c}-1.18 \mathrm{e}+00^{* *} \\
(4.79 \mathrm{e}-01)\end{array}$ & $\begin{array}{c}-1.01 \mathrm{e}+00^{* * *} \\
(3.87 \mathrm{e}-01)\end{array}$ & $\begin{array}{c}-1.04 \mathrm{e}+00^{* *} \\
(4.83 \mathrm{e}-01)\end{array}$ & $\begin{array}{c}-1.09 \mathrm{e}+00^{* * *} \\
(3.74 \mathrm{e}-01)\end{array}$ \\
\hline Shock $\omega_{t, R W}$ & $\begin{array}{c}-1.22 \mathrm{e}+00^{* * *} \\
(3.51 \mathrm{e}-01)\end{array}$ & $\begin{array}{c}-1.21 \mathrm{e}+00^{* * *} \\
(3.10 \mathrm{e}-01)\end{array}$ & $\begin{array}{c}-1.08 \mathrm{e}+00^{* *} \\
(4.41 \mathrm{e}-01)\end{array}$ & $\begin{array}{c}-1.15 \mathrm{e}+00^{* * *} \\
(3.59 \mathrm{e}-01)\end{array}$ & $\begin{array}{c}-9.78 \mathrm{e}-01^{* *} \\
(4.58 \mathrm{e}-01)\end{array}$ & $\begin{array}{c}-1.18 \mathrm{e}+00^{* * *} \\
(3.54 \mathrm{e}-01)\end{array}$ \\
\hline Shock $\omega_{t-1, M S}$ & & & & & $\begin{array}{c}1.95 \mathrm{e}-01 \\
(4.90 \mathrm{e}-01)\end{array}$ & $\begin{array}{l}-5.16 \mathrm{e}-02 \\
(3.38 \mathrm{e}-01)\end{array}$ \\
\hline Shock $\omega_{t-1, R W}$ & & & & & $\begin{array}{c}-9.29 \mathrm{e}-01^{* *} \\
(4.35 \mathrm{e}-01)\end{array}$ & $\begin{array}{c}-6.74 \mathrm{e}-01^{* *} \\
(3.34 \mathrm{e}-01)\end{array}$ \\
\hline Time Trend & $\begin{array}{l}-8.75 \mathrm{e}-03 \\
(1.02 \mathrm{e}-02)\end{array}$ & $\begin{array}{l}-6.82 \mathrm{e}-03 \\
(1.03 \mathrm{e}-02)\end{array}$ & $\begin{array}{c}6.87 \mathrm{e}-03 \\
(3.11 \mathrm{e}-02)\end{array}$ & $\begin{array}{c}1.25 \mathrm{e}-02 \\
(3.17 \mathrm{e}-02)\end{array}$ & $\begin{array}{l}-2.52 \mathrm{e}-02 \\
(4.25 \mathrm{e}-02)\end{array}$ & $\begin{array}{l}-3.95 \mathrm{e}-03 \\
(3.96 \mathrm{e}-02)\end{array}$ \\
\hline Time Trend ${ }^{2}$ & $\begin{array}{c}-5.41 \mathrm{e}-04^{* *} \\
(2.37 \mathrm{e}-04)\end{array}$ & $\begin{array}{c}-5.79 \mathrm{e}-04^{* *} \\
(2.34 \mathrm{e}-04)\end{array}$ & $\begin{array}{c}-1.44 \mathrm{e}-03 \\
(1.71 \mathrm{e}-03)\end{array}$ & $\begin{array}{l}-1.69 \mathrm{e}-03 \\
(1.69 \mathrm{e}-03)\end{array}$ & $\begin{array}{c}1.98 \mathrm{e}-04 \\
(2.23 \mathrm{e}-03)\end{array}$ & $\begin{array}{l}-7.55 \mathrm{e}-04 \\
(2.04 \mathrm{e}-03)\end{array}$ \\
\hline Time Trend ${ }^{3}$ & & & $\begin{array}{c}1.38 \mathrm{e}-05 \\
(2.60 \mathrm{e}-05)\end{array}$ & $\begin{array}{c}1.72 \mathrm{e}-05 \\
(2.54 \mathrm{e}-05)\end{array}$ & $\begin{array}{l}-8.88 \mathrm{e}-06 \\
(3.26 \mathrm{e}-05)\end{array}$ & $\begin{array}{c}3.61 \mathrm{e}-06 \\
(2.97 \mathrm{e}-05)\end{array}$ \\
\hline F-stat & 0.0146 & & 0.0195 & & 1.3904 & \\
\hline$\chi^{2}$-stat & & 0.0039 & & 0.0627 & & 1.5022 \\
\hline \multirow[t]{2}{*}{ p-value } & 0.9040 & 0.9505 & 0.8892 & 0.8023 & 0.2557 & 0.4719 \\
\hline & \multicolumn{6}{|c|}{ Supply: First-Stage Instrumenting Expected Price $\mathbb{E}\left[\left.p_{t}\right|_{t-1}\right]$} \\
\hline Shock $\omega_{t-1, M S}$ & $\begin{array}{c}-6.88 \mathrm{e}-01^{*} \\
(3.67 \mathrm{e}-01)\end{array}$ & $\begin{array}{c}-6.25 \mathrm{e}-01^{* *} \\
(3.15 \mathrm{e}-01)\end{array}$ & $\begin{array}{l}-4.91 \mathrm{e}-01 \\
(3.66 \mathrm{e}-01)\end{array}$ & $\begin{array}{l}-5.43 \mathrm{e}-01^{*} \\
(3.03 \mathrm{e}-01)\end{array}$ & $\begin{array}{l}-5.03 \mathrm{e}-01 \\
(3.64 \mathrm{e}-01)\end{array}$ & $\begin{array}{c}-5.43 \mathrm{e}-01^{*} \\
(3.11 \mathrm{e}-01)\end{array}$ \\
\hline Shock $\omega_{t-1, R W}$ & $\begin{array}{c}-8.56 \mathrm{e}-01^{* * *} \\
(3.00 \mathrm{e}-01)\end{array}$ & $\begin{array}{c}-7.00 \mathrm{e}-01^{* * *} \\
(2.59 \mathrm{e}-01)\end{array}$ & $\begin{array}{c}-1.15 \mathrm{e}+00^{* * *} \\
(3.25 \mathrm{e}-01)\end{array}$ & $\begin{array}{c}-9.46 \mathrm{e}-01^{* * *} \\
(2.76 \mathrm{e}-01)\end{array}$ & $\begin{array}{c}-1.01 \mathrm{e}+00^{* * *} \\
(3.37 \mathrm{e}-01)\end{array}$ & $\begin{array}{c}-9.97 \mathrm{e}-01^{* * *} \\
(2.88 \mathrm{e}-01)\end{array}$ \\
\hline Shock $\omega_{t-2, M S}$ & & & & & $\begin{array}{c}7.62 \mathrm{e}-03 \\
(3.61 \mathrm{e}-01)\end{array}$ & $\begin{array}{c}7.44 \mathrm{e}-02 \\
(2.88 \mathrm{e}-01)\end{array}$ \\
\hline Shock $\omega_{t-2, R W}$ & & & & & $\begin{array}{c}-5.75 \mathrm{e}-01^{*} \\
(3.28 \mathrm{e}-01)\end{array}$ & $\begin{array}{c}-6.07 \mathrm{e}-01^{* *} \\
(2.64 \mathrm{e}-01)\end{array}$ \\
\hline Shock $\omega_{t, M S}$ & $\begin{array}{l}-2.63 \mathrm{e}-01 \\
(3.64 \mathrm{e}-01)\end{array}$ & $\begin{array}{l}-2.64 \mathrm{e}-01 \\
(3.32 \mathrm{e}-01)\end{array}$ & $\begin{array}{l}-9.26 \mathrm{e}-02 \\
(3.61 \mathrm{e}-01)\end{array}$ & $\begin{array}{l}-9.33 \mathrm{e}-02 \\
(3.20 \mathrm{e}-01)\end{array}$ & $\begin{array}{l}-1.28 \mathrm{e}-01 \\
(3.50 \mathrm{e}-01)\end{array}$ & $\begin{array}{l}-1.38 \mathrm{e}-01 \\
(3.01 \mathrm{e}-01)\end{array}$ \\
\hline Shock $\omega_{t, R W}$ & $\begin{array}{c}-8.22 \mathrm{e}-01^{* * *} \\
(2.94 \mathrm{e}-01)\end{array}$ & $\begin{array}{c}-8.89 \mathrm{e}-01^{* * *} \\
(2.66 \mathrm{e}-01)\end{array}$ & $\begin{array}{c}-1.20 \mathrm{e}+00^{* * *} \\
(3.42 \mathrm{e}-01)\end{array}$ & $\begin{array}{c}-1.23 \mathrm{e}+00^{* * *} \\
(3.03 \mathrm{e}-01)\end{array}$ & $\begin{array}{c}-1.03 \mathrm{e}+00^{* * *} \\
(3.45 \mathrm{e}-01)\end{array}$ & $\begin{array}{c}-1.06 \mathrm{e}+00^{* * *} \\
(2.96 \mathrm{e}-01)\end{array}$ \\
\hline Time Trend & $\begin{array}{l}-1.31 \mathrm{e}-02 \\
(8.75 \mathrm{e}-03)\end{array}$ & $\begin{array}{l}-1.22 \mathrm{e}-02 \\
(7.94 \mathrm{e}-03)\end{array}$ & $\begin{array}{c}-7.37 \mathrm{e}-02^{* *} \\
(3.18 \mathrm{e}-02)\end{array}$ & $\begin{array}{c}-6.49 \mathrm{e}-02^{* *} \\
(2.78 \mathrm{e}-02)\end{array}$ & $\begin{array}{c}-7.10 \mathrm{e}-02^{*} \\
(3.77 \mathrm{e}-02)\end{array}$ & $\begin{array}{c}-7.35 \mathrm{e}-02^{* *} \\
(3.22 \mathrm{e}-02)\end{array}$ \\
\hline Time Trend ${ }^{2}$ & $\begin{array}{c}-3.73 \mathrm{e}-04^{*} \\
(2.00 \mathrm{e}-04)\end{array}$ & $\begin{array}{c}-3.95 \mathrm{e}-04^{* *} \\
(1.81 \mathrm{e}-04)\end{array}$ & $\begin{array}{l}2.90 \mathrm{e}-03^{*} \\
(1.66 \mathrm{e}-03)\end{array}$ & $\begin{array}{l}2.45 \mathrm{e}-03^{*} \\
(1.46 \mathrm{e}-03)\end{array}$ & $\begin{array}{c}2.72 \mathrm{e}-03 \\
(1.90 \mathrm{e}-03)\end{array}$ & $\begin{array}{l}2.85 \mathrm{e}-03^{*} \\
(1.63 \mathrm{e}-03)\end{array}$ \\
\hline Time Trend ${ }^{3}$ & & & $\begin{array}{c}-4.82 \mathrm{e}-05^{*} \\
(2.43 \mathrm{e}-05)\end{array}$ & $\begin{array}{c}-4.21 \mathrm{e}-05^{* *} \\
(2.14 \mathrm{e}-05)\end{array}$ & $\begin{array}{l}-4.48 \mathrm{e}-05 \\
(2.72 \mathrm{e}-05)\end{array}$ & $\begin{array}{c}-4.66 \mathrm{e}-05^{* *} \\
(2.33 \mathrm{e}-05)\end{array}$ \\
\hline F-stat & 0.1179 & & 1.5607 & & 0.8349 & \\
\hline$\chi^{2}$-stat & & 0.0326 & & 0.8421 & & 2.9795 \\
\hline p-value & 0.7323 & 0.8568 & 0.2158 & 0.3588 & 0.4385 & 0.2254 \\
\hline Observations & 42 & 42 & 42 & 42 & 41 & 41 \\
\hline Time Trend I & 2 & 2 & 3 & 3 & 3 & 3 \\
\hline Shock Lags K & 1 & 1 & 1 & 1 & 2 & 2 \\
\hline
\end{tabular}


Table 6: Sensitivity Checks: Elasticities Estimated using Jackknifed Yield Residuals

\begin{tabular}{|c|c|c|c|c|c|c|}
\hline & \multicolumn{6}{|c|}{$\overline{\overline{\text { Model }}}$} \\
\hline & 2SLS & 3SLS & 2SLS & \multirow[t]{2}{*}{ 3SLS } & 2SLS & \multirow[t]{2}{*}{ 3SLS } \\
\hline \multicolumn{5}{|c|}{ Panel A: Baseline } & & \\
\hline $\begin{array}{l}\text { Demand Elasticity } \\
\text { (s.e.) }\end{array}$ & $\begin{array}{c}-0.0505^{* * *} \\
(0.0190)\end{array}$ & $\begin{array}{c}-0.0554^{* * *} \\
(0.0167)\end{array}$ & $\begin{array}{c}-0.0641^{* *} \\
(0.0243)\end{array}$ & $\begin{array}{c}-0.0797^{* * *} \\
(0.0215)\end{array}$ & $\begin{array}{c}-0.0668^{* * *} \\
(0.0241)\end{array}$ & $\begin{array}{c}-0.0634^{* * *} \\
(0.0226)\end{array}$ \\
\hline Supply Elasticity & $0.1165^{* * *}$ & $0.1337^{* * *}$ & $0.0826^{* * *}$ & $0.0951^{* * *}$ & $0.0957^{* * *}$ & $0.0979^{* * *}$ \\
\hline (s.e.) & $(0.0286)$ & $(0.0241)$ & $(0.0217)$ & $(0.0189)$ & $(0.0208)$ & $(0.0189)$ \\
\hline Price Increase & 31.41 & 27.01 & 36.10 & 29.31 & 32.14 & 32.16 \\
\hline 95\% Conf. Int. & $(21.32,50.14)$ & $(20.69,36.62)$ & $(23.75,60.31)$ & $(22.01,40.80)$ & $(22.23,50.00)$ & $(22.79,48.40)$ \\
\hline \multicolumn{7}{|c|}{ Panel B: Caloric Shock Derived using Linear Time Trend } \\
\hline Demand Elasticity & $-0.0492^{* *}$ & $-0.0544^{* * *}$ & $-0.0590^{* *}$ & $-0.0715^{* * *}$ & $-0.0616^{* *}$ & $-0.0575^{* * *}$ \\
\hline (s.e.) & $(0.0192)$ & $(0.0169)$ & $(0.0234)$ & $(0.0211)$ & $(0.0234)$ & $(0.0220)$ \\
\hline Supply Elasticity & $0.1058^{* * *}$ & $0.1206^{* * *}$ & $0.0868^{* * *}$ & $0.1010^{* * *}$ & $0.1008^{* * *}$ & $0.1038^{* * *}$ \\
\hline (s.e.) & $(0.0261)$ & $(0.0219)$ & $(0.0230)$ & $(0.0194)$ & $(0.0229)$ & $(0.0206)$ \\
\hline Price Increase & 33.91 & 29.20 & 36.43 & 29.70 & 32.24 & 32.21 \\
\hline 95\% Conf. Int. & $(22.88,54.59)$ & $(22.32,39.68)$ & $(23.80,61.39)$ & $(22.33,41.26)$ & $(22.07,50.88)$ & $(22.67,48.94)$ \\
\hline \multicolumn{7}{|c|}{ Panel C: Caloric Shock Derived using Quadratic Area Trend } \\
\hline Demand Elasticity & $-0.0489^{* *}$ & $-0.0528^{* * *}$ & $-0.0614^{* *}$ & $-0.0740^{* * *}$ & $-0.0639^{* * *}$ & $-0.0595^{* * *}$ \\
\hline (s.e.) & $(0.0185)$ & $(0.0165)$ & $(0.0233)$ & $(0.0211)$ & $(0.0233)$ & $(0.0216)$ \\
\hline Supply Elasticity & $0.1171^{* * *}$ & $0.1318^{* * *}$ & $0.0856^{* * *}$ & $0.0970^{* * *}$ & $0.0988^{* * *}$ & $0.1013^{* * *}$ \\
\hline (s.e.) & $(0.0274)$ & $(0.0230)$ & $(0.0206)$ & $(0.0178)$ & $(0.0199)$ & $(0.0180)$ \\
\hline Price Increase & 31.51 & 27.66 & 35.85 & 29.95 & 31.96 & 32.15 \\
\hline 95\% Conf. Int. & $(21.66,49.45)$ & $(21.23,37.39)$ & $(24.04,58.22)$ & $(22.59,41.46)$ & $(22.44,48.72)$ & $(23.15,47.34)$ \\
\hline \multicolumn{7}{|c|}{ Panel D: Rescaled Caloric Conversion Factors to Equalize Average Prices } \\
\hline Demand Elasticity & $-0.0629^{* * *}$ & $-0.0578^{* * *}$ & $-0.0803^{* * *}$ & $-0.0794^{* * *}$ & $-0.0662^{* * *}$ & $-0.0655^{* * *}$ \\
\hline (s.e.) & $(0.0184)$ & $(0.0151)$ & $(0.0237)$ & $(0.0167)$ & $(0.0200)$ & $(0.0199)$ \\
\hline Supply Elasticity & $0.1247^{* * *}$ & $0.1347^{* * *}$ & $0.0716^{* * *}$ & $0.0783^{* * *}$ & $0.0808^{* * *}$ & $0.0801^{* * *}$ \\
\hline (s.e.) & $(0.0362)$ & $(0.0289)$ & $(0.0165)$ & $(0.0142)$ & $(0.0154)$ & $(0.0139)$ \\
\hline Price Increase & 28.15 & 26.64 & 34.27 & 32.18 & 35.13 & 35.38 \\
\hline 95\% Conf. Int. & $(18.71,46.27)$ & $(19.92,37.27)$ & $(23.97,52.50)$ & $(25.63,41.52)$ & $(25.44,51.32)$ & $(25.87,51.01)$ \\
\hline \multicolumn{7}{|c|}{ Panel E: Caloric Shock not Divided by Inventory } \\
\hline Demand Elasticity & $-0.0439 * *$ & $-0.0464^{* * *}$ & $-0.0555^{* *}$ & $-0.0654^{* * *}$ & $-0.0564^{* *}$ & $-0.0535^{* *}$ \\
\hline (s.e.) & $(0.0180)$ & $(0.0158)$ & $(0.0225)$ & $(0.0198)$ & $(0.0218)$ & $(0.0205)$ \\
\hline Supply Elasticity & $0.1219^{* * *}$ & $0.1376^{* * *}$ & $0.0870^{* * *}$ & $0.1001^{* * *}$ & $0.0991^{* * *}$ & $0.1031^{* * *}$ \\
\hline (s.e.) & $(0.0285)$ & $(0.0230)$ & $(0.0208)$ & $(0.0172)$ & $(0.0193)$ & $(0.0169)$ \\
\hline Price Increase & 31.61 & 27.70 & 37.01 & 30.87 & 33.43 & 32.89 \\
\hline 95\% Conf. Int. & $(21.55,50.13)$ & $(21.46,36.99)$ & $(24.67,60.68)$ & $(23.65,41.84)$ & $(23.51,50.83)$ & $(24.11,47.24)$ \\
\hline \multicolumn{7}{|c|}{ Panel F: Futures Price for Maize and Soybeans Traded in March } \\
\hline Demand Elasticity & $-0.0505^{* * *}$ & $-0.0554^{* * *}$ & $-0.0641^{* *}$ & $-0.0797^{* * *}$ & $-0.0668^{* * *}$ & $-0.0642^{* * *}$ \\
\hline (s.e.) & $(0.0190)$ & $(0.0167)$ & $(0.0243)$ & $(0.0215)$ & $(0.0241)$ & $(0.0226)$ \\
\hline Supply Elasticity & $0.1234^{* * *}$ & $0.1455^{* * *}$ & $0.0858^{* * *}$ & $0.1009^{* * *}$ & $0.0981^{* * *}$ & $0.1001^{* * *}$ \\
\hline (s.e.) & $(0.0323)$ & $(0.0268)$ & $(0.0232)$ & $(0.0199)$ & $(0.0218)$ & $(0.0197)$ \\
\hline Price Increase & 30.34 & 25.45 & 35.38 & 28.36 & 31.68 & 31.60 \\
\hline 95\% Conf. Int. & $(20.20,49.76)$ & $(19.40,34.71)$ & $(23.18,59.42)$ & $(21.35,39.31)$ & $(21.87,49.45)$ & $(22.33,47.74)$ \\
\hline Observations & 42 & 42 & 42 & 42 & 41 & 41 \\
\hline Time Trend I & 2 & 2 & 3 & 3 & 3 & 3 \\
\hline Shock Lags K & 1 & 1 & 1 & 1 & 2 & 2 \\
\hline
\end{tabular}


Table 7: Sensitivity Checks: Elasticities Estimated using Yield Shocks Attributable to Observed Weather Shocks

\begin{tabular}{|c|c|c|c|c|c|c|}
\hline & \multicolumn{6}{|c|}{$\overline{\text { Model }}$} \\
\hline & 2SLS & 3SLS & 2SLS & 3SLS & 2SLS & 3SLS \\
\hline \multicolumn{7}{|c|}{ Panel A: Baseline } \\
\hline \multirow{2}{*}{$\begin{array}{l}\text { Demand Elasticity } \\
\text { (s.e.) }\end{array}$} & $-0.0505^{* * *}$ & $-0.0554^{* * *}$ & $-0.0641^{* *}$ & $-0.0797^{* * *}$ & $-0.0668^{* * *}$ & $-0.0634^{* * *}$ \\
\hline & $(0.0190)$ & $(0.0167)$ & $(0.0243)$ & $(0.0215)$ & $(0.0241)$ & $(0.0226)$ \\
\hline \multirow{2}{*}{$\begin{array}{l}\text { Supply Elasticity } \\
\text { (s.e.) }\end{array}$} & $0.1165^{* * *}$ & $0.1337^{* * *}$ & $0.0826^{* * *}$ & $0.0951^{* * *}$ & $0.0957^{* * *}$ & $0.0979^{* * *}$ \\
\hline & $(0.0286)$ & $(0.0241)$ & $(0.0217)$ & $(0.0189)$ & $(0.0208)$ & $(0.0189)$ \\
\hline \multirow{3}{*}{$\begin{array}{l}\text { Price Increase } \\
\text { 95\% Conf. Int. }\end{array}$} & 31.41 & 27.01 & 36.10 & 29.31 & 32.14 & 32.16 \\
\hline & $(21.32,50.14)$ & $(20.69,36.62)$ & $(23.75,60.31)$ & $(22.01,40.80)$ & $(22.23,50.00)$ & $(22.79,48.40)$ \\
\hline & Panel B: & roduction $\mathrm{Sl}$ & ock Derived & sing Observe & Weather & \\
\hline \multirow{2}{*}{$\begin{array}{l}\text { Demand Elasticity } \\
\text { (s.e.) }\end{array}$} & -0.0315 & -0.0591 & -0.0324 & -0.0682 & -0.0404 & -0.0569 \\
\hline & $(0.1144)$ & $(0.0494)$ & $(0.1197)$ & $(0.0539)$ & $(0.0621)$ & $(0.0347)$ \\
\hline \multirow{2}{*}{$\begin{array}{l}\text { Supply Elasticity } \\
\text { (s.e.) }\end{array}$} & -1.8247 & $0.1532^{* * *}$ & 1.6023 & $0.1555^{* * *}$ & -0.2373 & -0.4045 \\
\hline & $(48.0201)$ & $(0.0388)$ & $(32.5143)$ & $(0.0461)$ & $(0.4016)$ & $(0.3542)$ \\
\hline \multirow{2}{*}{$\begin{array}{l}\text { Price Increase } \\
\text { 95\% Conf. Int. }\end{array}$} & 0.02 & 26.98 & -0.02 & 25.39 & 3.00 & -4.77 \\
\hline & $(-1.65,1.66)$ & $(14.88,55.91)$ & $(-2.43,2.47)$ & $(13.75,58.30)$ & $(-177.35,170.22)$ & $(-146.83,131.75)$ \\
\hline Observations & 41 & 41 & 41 & 41 & 40 & 40 \\
\hline Time Trend I & 2 & 2 & 3 & 3 & 3 & 3 \\
\hline Shock Lags K & 1 & 1 & 1 & 1 & 2 & 2 \\
\hline
\end{tabular}

Notes: Sensitivity checks of results from Table 3 to modeling yield shocks using observed weather outcomes. Caloric shocks in panel B are derived as follows: For the United States we fit a model that uses degree days and a quadratic in total precipitation following Schlenker and Roberts (2009), while rice and wheat are modeled using a quadratic in average temperature and total precipitation during the growing season. We estimate a quadratic in average temperature and total precipitation for a panel of all other countries that produces more than 1 percent of a particular crop. All other countries are lumped together as "Rest of World", where the weather variables are the area-weighted average of all countries. All regressions include a quadratic time trend. 
Table 8: Replication of Other Approaches: Demand and Supply of Calories

\begin{tabular}{|c|c|c|c|c|c|c|c|}
\hline & \multicolumn{2}{|c|}{ SUR - Price Not Instrumented } & \multicolumn{4}{|c|}{ Demand Instrumented / Supply Not Instrumented } \\
\hline & & (1) & $(2)$ & (3) & (4) & $(5)$ & (6) \\
\hline \multirow{9}{*}{ 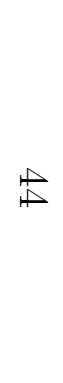 } & Demand Elasticity & $-0.0173^{*}$ & $-0.0187^{*}$ & $-0.0489^{* * *}$ & $-0.0489^{* * *}$ & $-0.0489^{* * *}$ & $-0.0655^{* * *}$ \\
\hline & (s.e.) & $(0.0094)$ & $(0.0098)$ & $(0.0180)$ & $(0.0180)$ & $(0.0180)$ & $(0.0243)$ \\
\hline & Supply Elasticity & 0.0159 & 0.0136 & 0.0226 & 0.0245 & 0.0238 & 0.0226 \\
\hline & (s.e.) & $(0.0182)$ & $(0.0162)$ & $(0.0239)$ & $(0.0251)$ & $(0.0274)$ & $(0.0239)$ \\
\hline & Price Increase & 197.31 & 191.37 & 146.21 & 124.40 & 75.41 & 80.69 \\
\hline & 95\% Conf. Int. & $(-694.47,1147.67)$ & $(-646.87,1145.45)$ & $(36.94,299.62)$ & $(35.79,294.97)$ & $(34.00,343.52)$ & $(31.62,209.22)$ \\
\hline & Time Trend $I$ & 2 & 3 & 2 & 2 & 2 & 3 \\
\hline & Shocks Lags $K$ & n.A. & n.A. & 1 & 1 & 1 & 2 \\
\hline & Supply Lags & n.A. & n.A. & 0 & 1 & 2 & 0 \\
\hline
\end{tabular}

Notes: The first two columns do not instrument price (which is arguably endogenous) and simply use the observed price in a year in both the supply and demand equation. The last four columns follow the approach of Nerlove (1958) and do not instrument futures prices in the supply equation. Following the literature, lagged supply quantities are included in some regressions. 
Table 9: Acreage Changes in Response to Past Caloric Shocks and Instrumented Price

\begin{tabular}{|c|c|c|c|c|c|c|}
\hline & 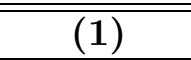 & 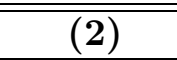 & 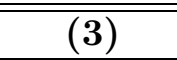 & 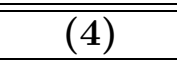 & 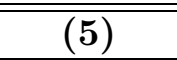 & 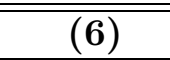 \\
\hline & \multicolumn{6}{|c|}{ Panel A: World Growing Area } \\
\hline Shock $\omega_{t-1}$ & $\begin{array}{c}-0.0599^{* * *} \\
(0.0147)\end{array}$ & $\begin{array}{c}-0.0620^{* * *} \\
(0.0186)\end{array}$ & & & & \\
\hline $\mathbb{E}\left[\left.p_{t}\right|_{t-1}\right]$ & & & $\begin{array}{c}0.0725^{* * *} \\
(0.0146)\end{array}$ & $\begin{array}{c}0.0634^{* * *} \\
(0.0148)\end{array}$ & $\begin{array}{c}0.0756^{* * *} \\
(0.0130)\end{array}$ & $\begin{array}{c}0.0750^{* * *} \\
(0.0140)\end{array}$ \\
\hline Shock $\omega_{t-1}$ & \multicolumn{6}{|c|}{$\begin{array}{l}\text { Panel B: Growing Area of United States } \\
-0.2512^{* * *} \\
(0.0826)\end{array}$} \\
\hline $\mathbb{E}\left[\left.p_{t}\right|_{t-1}\right]$ & & & $\begin{array}{c}0.3200^{* * *} \\
(0.0562)\end{array}$ & $\begin{array}{c}0.2569^{* * *} \\
(0.0566)\end{array}$ & $\begin{array}{c}0.3350^{* * *} \\
(0.0504)\end{array}$ & $\begin{array}{c}0.2967^{* * *} \\
(0.0527)\end{array}$ \\
\hline Shock $\omega_{t-1}$ & $\begin{array}{c}-0.3111^{* * *} \\
(0.0731)\end{array}$ & $\begin{array}{r}\text { Pan } \\
-0.2304^{* *} \\
(0.0897)\end{array}$ & C: Grow & ng Area c & Brazil & \\
\hline $\mathbb{E}\left[\left.p_{t}\right|_{t-1}\right]$ & & & $\begin{array}{c}0.3768^{* * *} \\
(0.1096)\end{array}$ & $\begin{array}{c}0.2356^{* *} \\
(0.0947)\end{array}$ & $\begin{array}{c}0.3681^{* * *} \\
(0.0986)\end{array}$ & $\begin{array}{c}0.2233^{* *} \\
(0.0877)\end{array}$ \\
\hline Shock $\omega_{t-1}$ & $\begin{array}{l}-0.0256 \\
(0.0272)\end{array}$ & $\begin{array}{r}\text { Pan } \\
-0.0424 \\
(0.0340)\end{array}$ & D: Grow & ng Area & f China & \\
\hline $\mathbb{E}\left[\left.p_{t}\right|_{t-1}\right]$ & & & $\begin{array}{c}0.0311 \\
(0.0299)\end{array}$ & $\begin{array}{c}0.0434 \\
(0.0311)\end{array}$ & $\begin{array}{c}0.0371 \\
(0.0265)\end{array}$ & $\begin{array}{l}0.0713^{* *} \\
(0.0277)\end{array}$ \\
\hline Shock $\omega_{t-1}$ & $\begin{array}{l}-0.0124 \\
(0.0262)\end{array}$ & $\begin{array}{r}\text { Pan } \\
-0.0049 \\
(0.0331)\end{array}$ & l E: Grow & ing Area & f India & \\
\hline $\mathbb{E}\left[\left.p_{t}\right|_{t-1}\right]$ & & & $\begin{array}{c}0.0150 \\
(0.0296)\end{array}$ & $\begin{array}{c}0.0050 \\
(0.0315)\end{array}$ & $\begin{array}{c}0.0259 \\
(0.0266)\end{array}$ & $\begin{array}{c}0.0065 \\
(0.0287)\end{array}$ \\
\hline Shock $\omega_{t-1}$ & $\begin{array}{l}-0.1078^{*} \\
(0.0553)\end{array}$ & $\begin{array}{c}\text { Panel } \\
-0.1636^{* *} \\
(0.0682)\end{array}$ & F: Growir & Area of & Thailand & \\
\hline $\mathbb{E}\left[\left.p_{t}\right|_{t-1}\right]$ & & & $\begin{array}{l}0.1306^{*} \\
(0.0672)\end{array}$ & $\begin{array}{l}0.1673^{* *} \\
(0.0730)\end{array}$ & $\begin{array}{l}0.0979^{*} \\
(0.0591)\end{array}$ & $\begin{array}{c}0.1020 \\
(0.0640)\end{array}$ \\
\hline Observation & 42 & 42 & 42 & 42 & 41 & 41 \\
\hline Time Trend I & 2 & 3 & 2 & 3 & 2 & 3 \\
\hline Shock Lags K & n.a. & n.a. & 1 & 1 & 2 & 2 \\
\hline
\end{tabular}


Table 10: Calories per Acre in 2007

\begin{tabular}{|c|c|c|c|c|}
\hline$\overline{\text { Country }}$ & Maize & Wheat & "Rice & Soybeans \\
\hline Argentina & 16.96 & 5.82 & & 8.59 \\
\hline Australia & & 3.61 & & \\
\hline Bangladesh & & & 8.16 & \\
\hline Brazil & 8.91 & & 8.10 & 8.83 \\
\hline Canada & 20.01 & 5.37 & & 8.39 \\
\hline China & 13.29 & 9.89 & 13.6 & 6.09 \\
\hline France & 22.11 & 15.60 & & \\
\hline Germany & & 16.93 & & \\
\hline Hungary & 14.14 & & & \\
\hline India & 5.16 & 6.24 & 6.82 & 3.44 \\
\hline Indonesia & 8.74 & & 9.64 & \\
\hline Iran & & 5.04 & & \\
\hline Italy & 22.93 & 7.58 & & \\
\hline Japan & & & 13.33 & \\
\hline Kazakhstan & & 2.72 & & \\
\hline Korea & & & 13.22 & \\
\hline Mexico & 7.30 & & & \\
\hline Myanmar & & & 7.77 & \\
\hline Pakistan & & 5.64 & 6.26 & \\
\hline Philippines & & & 7.44 & \\
\hline Poland & & 7.92 & & \\
\hline Rest of World & 6.27 & 6.22 & 6.42 & 5.78 \\
\hline Romania & 7.13 & 4.98 & & \\
\hline Russian Federation & & 4.60 & & \\
\hline South Africa & 7.43 & & & \\
\hline Spain & & 6.31 & & \\
\hline Thailand & & & 6.01 & \\
\hline Turkey & & 4.71 & & \\
\hline Ukraine & & 5.63 & & \\
\hline United Kingdom & & 17.92 & & \\
\hline United States of America & 23.04 & 6.00 & 16.21 & 9.12 \\
\hline Vietnam & & & 10.74 & \\
\hline
\end{tabular}

Notes: Table gives the number of million calories per hectare using the predicted yield (along the trend) in 2007. 